\title{
Protein Kinase A Deregulation in the Medial Prefrontal Cortex Impairs Working Memory in Murine Oligophrenin-1 Deficiency
}

\author{
[CChun-Lei Zhang, ${ }^{1,5}$ Mattia Aime, ${ }^{1}$ Emilie Laheranne, ${ }^{1}$ Xander Houbaert, ${ }^{1}$ Hajer El Oussini, ${ }^{1}$ Christelle Martin, ${ }^{1}$ \\ Marilyn Lepleux, ${ }^{1}$ Elisabeth Normand, ${ }^{2}$ Jamel Chelly, ${ }^{3,4}{ }^{\circ}$ Etienne Herzog, ${ }^{1}{ }^{\odot P i e r r e ~ B i l l u a r t, ~}{ }^{3}$ and Yann Humeau ${ }^{1}$ \\ ${ }^{1}$ Team Synapse in Cognition and ${ }^{2}$ Pole In Vivo, Institut Interdisciplinaire de Neuroscience, Centre National de la Recherche Scientifique Centre National de \\ la Recherche Scientifique Unité Mixte de Recherche 5297, Université de Bordeaux, 33077 Bordeaux cedex, France, ${ }^{3}$ Centre National de la Recherche \\ Scientifique, Université Paris Descartes, Institut National de la Santé et de la Recherche Médicale, Unité Mixte de Recherche 8104, Institut Cochin, 75014 \\ Paris, France, ${ }^{4 T e a m ~ m e ́ d e c i n e ~ " t r a n s l a t i o n n e l l e ~ e t ~ n e u r o g e ́ n e ́ t i q u e, " ~ I n s t i t u t ~ d e ~ G e ́ n e ́ t i q u e ~ e t ~ d e ~ B i o l o g i e ~ M o l e ́ c u l a i r e ~ e t ~ C e l l u l a i r e, ~ C e n t r e ~ N a t i o n a l ~ d e ~ l a ~}$ \\ Recherche Scientifique Unité Mixte de Recherche 7104, Institut National de la Santé et de la Recherche Médicale U964, Université de Strasbourg, 75015 \\ Illkirch, France, and ${ }^{5}$ Neural Circuits for Spatial Navigation and Memory, Department of Neuroscience, Institut Pasteur, 67400 Paris, France
}

Classical and systems genetics have identified wide networks of genes associated with cognitive and neurodevelopmental diseases. In parallel to deciphering the role of each of these genes in neuronal or synaptic function, evaluating the response of neuronal and molecular networks to gene loss of function could reveal some pathophysiological mechanisms potentially accessible to nongenetic therapies. Loss of function of the Rho-GAP oligophrenin-1 is associated with cognitive impairments in both human and mouse. Upregulation of both PKA and ROCK has been reported in $O p h n 1^{-l y}$ mice, but it remains unclear whether kinase hyperactivity contributes to the behavioral phenotypes. In this study, we thoroughly characterized a prominent perseveration phenotype displayed by $O p h n 1$-deficient mice using a Y-maze spatial working memory (SWM) test. We report that $O p h n 1$ deficiency in the mouse generated severe cognitive impairments, characterized by both a high occurrence of perseverative behaviors and a lack of deliberation during the SWM test. In vivo and in vitro pharmacological experiments suggest that PKA dysregulation in the MPFC underlies cognitive dysfunction in Ophn1-deficient mice, as assessed using a delayed spatial alternation task results. Functionally, mPFC neuronal networks appeared to be affected in a PKAdependent manner, whereas hippocampal-PFC projections involved in SWM were not affected in $0 p h n 1^{-/ y}$ mice. Thus, we propose that discrete gene mutations in intellectual disability might generate "secondary" pathophysiological mechanisms, which are prone to become pharmacological targets for curative strategies in adult patients.

Key words: delayed spatial alternation; dorsal hippocampus; oligophrenin-1; prefrontal cortex; protein kinase A; spatial working memory

Significance Statement

Here we report that $O p h n 1$ deficiency generates severe impairments in performance at spatial working memory tests, characterized by a high occurrence of perseverative behaviors and a lack of decision making. This cognitive deficit is consecutive to PKA deregulation in the mPFC that prevents $0 p h n 1 \mathrm{KO}$ mice to exploit a correctly acquired rule. Functionally, mPFC neuronal networks appear to be affected in a PKA-dependent manner, whereas behaviorally important hippocampal projections were preserved by the mutation. Thus, we propose that discrete gene mutations in intellectual disability can generate "secondary" pathophysiological mechanisms prone to become pharmacological targets for curative strategies in adults.

\section{Introduction}

Loss of function of the Rho-GAP oligophrenin-1 is associated with cognitive impairments (Billuart et al., 1998; van Bokhoven,

Received Feb. 7, 2017; revised Sept. 5, 2017; accepted Sept. 28, 2017

Author contributions: C.-L.Z., H.E.O., J.C., E.H., P.B., and Y.H. designed research; C.-L.Z., M.A., E.L., X.H., H.E.O., C.M., M.L., E.N., and Y.H. performed research; J.C. contributed unpublished reagents/analytic tools; C.-L.Z., M.A., H.E.O., and Y.H. analyzed data; C.-L.Z., H.E.O., E.H., and Y.H. wrote the paper.

This work was supported by Agence Nationale de la Recherche Grant ANR-2010-BLAN-1434-01 to Y.H., and the program investissement d'avenir (Labex Brain). We thank Dr. Pierre Trifilieff for fruitful discussions; Dr. Frédéric
2011) and more rarely to autism spectrum disorder and schizophrenia (Piton et al., 2011). Mice with a null Ophn1 mutation also

\footnotetext{
Gambino for helping with statistics; Dr. Andrew Penn for text improvement; and Prof. Benjamin K. Yee for technical advice on setting up the $Y$-maze experiments.

The authors declare no competing financial interests.

Correspondence should be addressed to Dr. Yann Humeau, Unité Mixte de Recherche 5297, Institut Interdisciplinaire de Neuroscience, Bâtiment Neurocampus, 146 rue Léo Saignat, 33077 Bordeaux cedex, France. E-mail: yann.humeau@u-bordeaux.fr.

DOI:10.1523/JNEUROSCI.0351-17.2017

Copyright $\odot 2017$ the authors $\quad 0270-6474 / 17 / 3711114-13 \$ 15.00 / 0$
} 
display a number of behavioral and learning deficits (Khelfaoui et al., 2007). Ophn 1 is a synaptic protein controlling synaptic vesicle trafficking, AMPAR recruitment, and mGluR1-dependent LTD (Nadif Kasri et al., 2009, 2011; Nakano-Kobayashi et al., 2009, 2014; Di Prisco et al., 2014). Ophn1 deficiency in mice has been associated with hyperactivity of Rho-associated protein kinase (ROCK) and cAMP-dependent protein kinase A (PKA) (Khelfaoui et al., 2007, 2014), possibly due to the loss of function of Rho-GAP activity and phosphorylation-based feedback controlling Rho A (Nusser et al., 2006). Interestingly, acute and chronic pharmacological treatments suggested that inhibition of PKA/ ROCK activities by the ROCK inhibitor Y27632 improves some of the functional and behavioral deficits observed in ophn1 KO mice (Powell et al., 2012; Khelfaoui et al., 2014; Meziane et al., 2016). However, actual data do not establish how hyperphosphorylation in discrete neuronal networks generates specific behavioral deficits.

$\mathrm{mPFC}$ and its connections with other brain regions play a crucial role in allowing meta-cognitive actions, such as working memory, behavioral flexibility (Kesner and Churchwell, 2011), and capacities that are impaired in mental disorders (Geurts et al., 2004; Rolls et al., 2008; Sumiyoshi et al., 2011). In rodents, researchers use a delayed spatial alternation task (DSA) to test spatial working memory (SWM), of which connections between the hippocampus and mPFC have been shown to play a fundamental role (Laroche et al., 2000; Wang and Cai, 2006). Also, in vivo electrophysiological recordings during the DSA task revealed a decision point before the bifurcation area of the maze, where synchronization of hippocampus-PFC neuronal activities occurs in the theta $(4-10 \mathrm{~Hz})$ range (Benchenane et al., 2010). It has been proposed that this would allow animals to deliberate to choose the rewarding arm. Interestingly, this deliberation process is characterized by "vicarious trial and error" (VTE) behaviors, the occurrence of which strongly correlates with the success rate (Wikenheiser and Redish, 2015; Redish, 2016).

Computational studies proposed that working memory impairment could be consecutive to aberrant signal-to-noise ratios within PFC networks (Rolls et al., 2008). In rodents, SWM performance is altered in excessive, but not in depressed, PKA activity (Taylor et al., 1999; Arnsten et al., 2005). Meanwhile, some form of PKA-dependent plasticity has been described at hippocampus-PFC projections (Jay et al., 1998). It was also suggested that PKA activity could influence the signal-to-noise ratio within PFC networks, physiologically relaying the dopaminergic activation (Rolls et al., 2008).

Here, we observed that Ophn1-deficient mice performed poorly in Y-maze-based SWM tests. We then combined in vivo and in vitro strategies to test whether the poor behavioral performance results from the hyperactivity of PKA in the PFC region.

\section{Materials and Methods}

\section{Subjects}

A total of 73 Ophn1 wild-type (WT) and 73 Ophn1 knock-out (KO) male littermates were used in this study. All animals are on C57BL/6N background, selected from 2 to 3 months old, and housed in $12 \mathrm{~h}: 12 \mathrm{~h} \mathrm{light/}$ dark cycle with ad libitum feeding. Every effort was made to minimize the number of animals used and their suffering. The experimental design and all procedures were in accordance with the European Guide for the care and use of laboratory animals and the animal care guidelines issued by the animal experimental ethics committee of Bordeaux Universities (CE50; APAFIS 2572).

\section{Behavioral protocols}

Our Y-maze consists of three arms ( $40 \mathrm{~cm}$ long, $10 \mathrm{~cm}$ wide, $15 \mathrm{~cm}$ high, $120^{\circ}$ between) made of white PVC material. Between trials, the maze was wiped by $4 \%$ acetic acid to avoid odor-based bias. Allocation of the starting arm was varied and counterbalanced within groups. The room light was weak and balanced, and a digital camera located $2 \mathrm{~m}$ above the maze was used to record animal trajectories.

Spontaneous alternation. A cohort of mice was placed in the room for $30 \mathrm{~min}$ before each mouse was positioned at the end of one starting arm and allowed to freely explore the maze for $10 \mathrm{~min}$. The Y-maze was located on the ground with prominent surrounding visual cues. Instinctively, mice are willing to explore the new environment, thus naturally alternating between arms. Success rate was calculated by dividing the number of correct choice over the total number of trials per session. An entry occurs when all four paws of the animals were within the arm.

Spatial novelty test. Another cohort of mice was habituated to the room for $30 \mathrm{~min}$. Mice were then assigned to explore two arms for $5 \mathrm{~min}$ : the "starting" arm and another that will become the "familiar" arm. The third arm, which will become the "novel" arm, was blocked by a sliding door. After returning back to the home cage for $10 \mathrm{~min}$, mice were then allowed to explore the entire maze for $2 \mathrm{~min}$. The time spent in each of the three arms was measured and the number of entries were counted.

DSA test. The DSA task is a delayed non-matching-to-place task extensively described and used to assess for PFC function (Taylor et al., 1999; Wang and Cai, 2006). To improve animal motivation, mice were handled and food restricted to maintain $\sim 85 \%$ weight. In the initial week, mice would perform two periods of habituation. In the first step, on a daily basis, each mouse was allowed to explore the maze twice for 10 min with $3 \mathrm{~h}$ interval. The food wells in the three-arm ends were baited with rewards, and mice were trained until they were capable of quickly obtaining the food reward. Then in the second step, one arm was set as the "starting" arm, the two others as the "baited" ones. A total of 10 runs were performed in $2 \mathrm{~d}$ ( 5 runs per day, at least $30 \mathrm{~min}$ interval between each run). The mice had to learn to alternate between "right-left or left-right" to get the bait with a time limit of $1 \mathrm{~min}$. To avoid a rewarding odor-based bias to mice choices, three bigger pieces of reward were positioned behind each arm end outside of the maze.

In the second week, the learning phase lasts 4 consecutive days. During this phase, the mice received two sessions per day ( $3 \mathrm{~h}$ interval between sessions), each composed of 10 trials (see Fig. 1). From Trial 0, mice run from a starting arm. One of two food-rewarded arms was closed, and mice were forced to get the reward in the opposite arm. In the next 9 successive trials, mice must alternate between right and left arm to find the reward. A trial may include up to 6 runs ( $30 \mathrm{~s}$ delay between runs, 5 consecutive errors allowed, before being forced to enter the rewarding arm). The success rate is calculated as the number of successful choices/ the total number of choices. We also ranked the errors from 1 to 5 to evaluate the perseveration of mice in repeating wrong choices (Wang and Cai, 2006). Food wells were changed in each trail, and arms were wiped by $4 \%$ acetic acid after each run. Between sessions, the maze was rotated, and starting arm was randomly chosen and balanced between animals.

\section{Cannula implantation}

At first, mice were treated with buprenorphine $(0.1 \mathrm{mg} / \mathrm{kg}$, i.p. $)$ and positioned in a stereotaxic apparatus (David Kopf Instruments), on a $33^{\circ} \mathrm{C}-35^{\circ} \mathrm{C}$ heating pad, and maintained under continuous isoflurane anesthesia. Stainless-steel guide cannulae (26 gauge; Plastics One) were bilaterally implanted above the medial PFC: anteroposterior 1.9-2.1 $\mathrm{mm}$, mediolateral $\pm 2.1-2.3 \mathrm{~mm}$, dorsoventral $-1.5 \mathrm{~mm}$, with $\pm 30^{\circ}$ angle, and/or dorsal hippocampus (dHPC): anteroposterior $-1.8-2.0$ $\mathrm{mm}$, mediolateral $\pm 2.2-2.5 \mathrm{~mm}$, dorsoventral $-0.5 \mathrm{~mm}$, with $\pm 30^{\circ}$ angle. The cannula was fixed to the skull using dental cement (SuperBond, Sun Medical). A dummy cannula was inserted into the guide cannula to reduce the risk of infection. A delay of 3-4 weeks for surgery recovery was respected before the food deprivation began, during which the body weight of mice was checked daily.

\section{Drug administration}

To reduce stress during drug injection, mice were trained on a daily basis for dummy cannula removal/insertion. To perform freely moving drug injection, the dummy cannula was replaced by an infusion cannula (33 gauge; connected to a $1 \mu \mathrm{l}$ Hamilton syringe via polyethylene tubing) 
Table 1. Statistics

\begin{tabular}{|c|c|c|c|c|c|}
\hline Tested condition & Figure & Test & Characteristics & $p$ & Beta power \\
\hline \multicolumn{6}{|l|}{ Figure 1} \\
\hline Success rate WT\#5 vs K0\#5 & $1 C 1$ & $\chi^{2}$ & 11,$960 ; 1 \mathrm{df}$ & $<0.001$ & 0.950 \\
\hline Success rate WT\#1 vs WT\#5 & $1 C 1$ & $x^{2}$ & 17,$172 ; 1 \mathrm{df}$ & $<0.001$ & 0.993 \\
\hline Success rate K0\#1 vs KO\#5 & $1 C 1$ & $x^{2}$ & 0,$577 ; 1 \mathrm{df}$ & 0.447 & 0.110 \\
\hline High rank errors WT\#1 vs WT\#5 & $1 C 2$ & $x^{2}$ & 10,$179 ; 1 \mathrm{df}$ & $<0.001$ & 0.910 \\
\hline High rank errors K0\#1 vs K0\#5 & 102 & $x^{2}$ & 0,$166 ; 1 \mathrm{df}$ & 0.683 & 0.065 \\
\hline High rank errors WT\#5 vs KO\#5 & $1 C 2$ & Mann-Whitney Rank Sum Test & 2 groups: WT high rank error and KO high rank error & $<0.001$ & - \\
\hline \multicolumn{6}{|l|}{ Figure 2} \\
\hline Entries (total) & $2 A$ & $t$ test & 2 groups: WT and KO total & 0.163 & - \\
\hline Turning preference (right/left) & $2 B$ & $t$ test & 2 groups: WT and $K 0$ ratios & 0.425 & - \\
\hline Novel arm preference & $2 C$ & $t$ test & 2 groups: WT and KO novel & 0.875 & - \\
\hline Regular choice probability & $2 D$ & $t$ test & 2 groups: WT and KO regular & $<0.001$ & - \\
\hline \multicolumn{6}{|l|}{ Figure 3} \\
\hline Wavering WT vs KO & $3 A 2$ & Z-test & 7,$317 ; 1 \mathrm{df}$ & $<0.001$ & 1 \\
\hline Success rate WTw vs KOw & $3 B 1$ & $\chi^{2}$ & 9,$443 ; 1 \mathrm{df}$ & 0.002 & 0.886 \\
\hline WTw vs KOw & $3 B 3$ & $t$ test & & $<0.001$ & - \\
\hline \multicolumn{6}{|l|}{ Fiqure 4} \\
\hline \multirow[t]{2}{*}{ Spiking activity WT vs KO } & $4 B$ & Two-way ANOVA & Factor A: genotype & 0482 & 0.05 \\
\hline & & & Factor B: injected current & $<0.001$ & 1 \\
\hline \multirow[t]{2}{*}{ Input- output curves WT vs KO } & $4 C 2$ & Two-way ANOVA & Factor A: genotype & 0365 & 0.05 \\
\hline & & & Factor B: stimulation power & $<0.001$ & 0.995 \\
\hline FFI WT vs KO & $4 C 3$ & Mann-Whitney Rank Sum Test & 2 groups: WT I/E and KO I/E & 0.341 & - \\
\hline \multicolumn{6}{|l|}{ Figure 5} \\
\hline SEPSP frequency WT vs KO & $5 A 2$ & Mann-Whitney Rank Sum Test & 2 groups: WT frequency and KO frequency & 0.004 & - \\
\hline Total labeling WT vs KO & $5 B 3$ & Mann-Whitney Rank Sum Test & 2 groups: WT intensity and KO intensity & 0.049 & - \\
\hline sEPSC frequency WT vs KO Control & $5 C 2$ & Mann-Whitney Rank Sum Test & 2 groups: WT frequency and KO frequency & 0.289 & - \\
\hline sEPSC frequency WT vs KO H89 & $5 C 2$ & Mann-Whitney Rank Sum Test & 2 groups: WT frequency and KO frequency & 0.007 & - \\
\hline sEPSC frequency WT vs KO FSK & $5 C 2$ & Mann-Whitney Rank Sum Test & 2 groups: WT frequency and K0 frequency & 0.798 & - \\
\hline \multicolumn{6}{|l|}{ Figure 6} \\
\hline Success rate WT before/drug/after & $6 B-C 1$ & $\chi^{2}$ & 17,$739 ; 2 \mathrm{df}$ & $<0.001$ & 0.982 \\
\hline High rank errors WT before/drug/after & $6 B-C 2$ & $x^{2}$ & 12,$298 ; 2 \mathrm{df}$ & 0.002 & 0.904 \\
\hline Wavering WT before/drug/after & $6 B-E 1$ & $x^{2}$ & 20,$427 ; 2 \mathrm{df}$ & $<0.001$ & 0.993 \\
\hline Choice accuracy WT before/drug/after & $6 B-E$ & $\chi^{2}$ & 0,$486 ; 2 \mathrm{df}$ & 0.784 & 0.085 \\
\hline \multicolumn{6}{|l|}{ Figure 7} \\
\hline Success rate WT before/drug/after & $7 C 1$ & $\chi^{2}$ & 0,$759 ; 2 \mathrm{df}$ & 0.684 & 0.107 \\
\hline Success rate $\mathrm{KO}$ before/drug/after & $7 C 1$ & $x^{2}$ & 31,$878 ; 2 \mathrm{df}$ & $<0.001$ & 1 \\
\hline Wavering K0, 5 conditions & $7 E 2$ & $x^{2}$ & 58,$430 ; 4 \mathrm{df}$ & $<0.001$ & 1 \\
\hline Choice accuracy KOw, 5 conditions & $7 E 3$ & $x^{2}$ & 32,$666 ; 4 \mathrm{df}$ & $<0.001$ & 0.999 \\
\hline
\end{tabular}

projecting out of the guide cannula with $1.5-2 \mathrm{~mm}$ to target $\mathrm{mPFC}$ or dHPC. Drug doses have been used previously (Taylor et al., 1999): cAMPS-Rp, triethylammonium salt $(10 \mu \mathrm{g} / \mu \mathrm{l}$ in saline), cAMPS-Sp triethylammonium salt $(1 \mu \mathrm{g} / \mu \mathrm{l})$, and 6-BNZ-cAMP $\mathrm{N}^{6}$-benzoyladenosine $-3^{\prime}, 5^{\prime}$-cyclic monophosphate sodium salt $(10 \mu \mathrm{g} / \mu \mathrm{l}$ in saline) were obtained from Tocris Bioscience and were infused bilaterally at a rate of $0.15 \mu \mathrm{l} / \mathrm{min}$ and a volume of $300-400 \mathrm{nl}$ per side by an automatic pump (Legato 100, KD Scientific), $30 \mathrm{~min}$ before testing. To allow the penetration of drug, the injector was maintained for an additional $3 \mathrm{~min}$. After the injection procedure, animals were placed back in their home cage.

In vitro electrophysiological recordings

Acute slice preparation. Fresh slices were obtained from 4- to 5-monthold Ophn1 WT and KO mice as described previously (Houbaert et al., 2013). All recordings were performed on mPFC-containing coronal slices (anteroposterior 1.3-2 mm). Briefly, mice were anesthetized by intraperitoneal injection of a mixture of ketamine $(10 \mathrm{mg} / \mathrm{ml}) / x y l a z i n e$ $(1 \mathrm{mg} / \mathrm{ml})$ before an intracardiac perfusion with a refrigerated bubbled (carbogen: $95 \% \mathrm{O}_{2} / 5 \% \mathrm{CO}_{2}$ ) sucrose solution containing the following (in $\mathrm{mM}$ ): $2.7 \mathrm{KCl}, 26 \mathrm{NaHCO}_{3}, 1.25 \mathrm{NaH}_{2} \mathrm{PO}_{4}, 10$ glucose, 220 sucrose, $0.2 \mathrm{CaCl}_{2}$, and $6 \mathrm{MgCl}_{2}$. Then, the brain was sliced (300 $\mu \mathrm{m}$ thickness) with a vibratome (Leica VT1200s) at $4^{\circ} \mathrm{C}$ in sucrose solution. Slices were then maintained for $45 \mathrm{~min}$ at $37^{\circ} \mathrm{C}$ in an interface chamber with ACSF containing the following (in mM): $124 \mathrm{NaCl}, 2.7 \mathrm{KCl}, 2 \mathrm{CaCl}_{2}, 10$ $\mathrm{MgSO}_{4} 7 \mathrm{H}_{2} \mathrm{O}, 26 \mathrm{NaHCO}_{3}, 1.25 \mathrm{NaH}_{2} \mathrm{PO}_{4}, 18.6$ glucose, and 2.25 ascor- bic acid and equilibrated with $95 \% \mathrm{O}_{2} / 5 \% \mathrm{CO}_{2}$. Recordings were performed with standard ACSF (Humeau et al., 2005).

Electrophysiological recordings. Synaptic activities and cellular properties of mPFC neuronal cells were recorded using classical whole-cell patch-clamp techniques previously described (Humeau et al., 2005; Houbaert et al., 2013; Zhang et al., 2015). Cells were recorded in currentclamp (spiking activities, spontaneous EPSPs) or voltage-clamp mode (synaptic conductances), respectively, using K-gluconate-based (in $\mathrm{mm}$ as follows: $140 \mathrm{~K}$-gluconate, 5 QX314-Cl, 10 HEPES, 10 phosphocreatine, $4 \mathrm{Mg}$-ATP, and $0.3 \mathrm{Na}-\mathrm{GTP}$, pH adjusted to 7.25 with $\mathrm{KOH}, 295$ $\mathrm{mOsm}$ ) and Cs-methylsulfonate-based (in $\mathrm{mm}$ as follows: $140 \mathrm{Cs}-$ methylsulfonate, 5 QX314-Cl, 10 HEPES, 10 phosphocreatine, 4 MgATP, and 0.3 Na-GTP, pH adjusted to 7.25 with $\mathrm{CsOH}, 295 \mathrm{mOsm}$ ) intracellular recording solutions.

\section{Optogenetic-based experiments}

Adeno-associated viruses (AAV2/9.CAG.ChR2-Venus.W.SV40-p1468, ref Addgene-20071, 5.82 $\mathrm{E}^{12}$ vector genomes $(\mathrm{vg}) / \mathrm{ml}$ ) were packaged at the University of Pennsylvania Vector Core. At $\sim 2$ months of age, mice $(>20 \mathrm{~g})$ were prepared for the stereotaxic injection. Beforehand, mice were treated with buprenorphine $(0.1 \mathrm{mg} / \mathrm{kg}$, i.p.) and positioned in a stereotaxic apparatus (David Kopf Instruments) under continuous anesthesia with isoflurane. During the surgery, the mice were warmed on a $33^{\circ} \mathrm{C}-35^{\circ} \mathrm{C}$ heating pad. The virus was bilaterally pressure-injected through glass pipettes (Hirschmann Laborgerate, ringcaps, tips pulled O.D $30-40 \mu \mathrm{m}$ ) using a Picosprizer (Parker). The positions of bregma 
A1

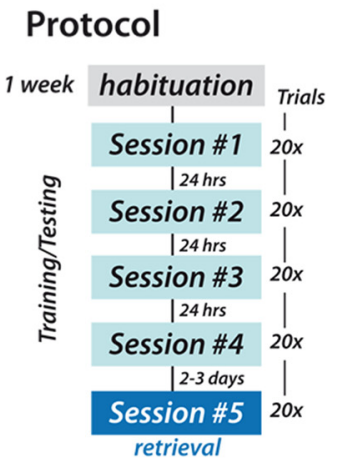

B Individual Scoring
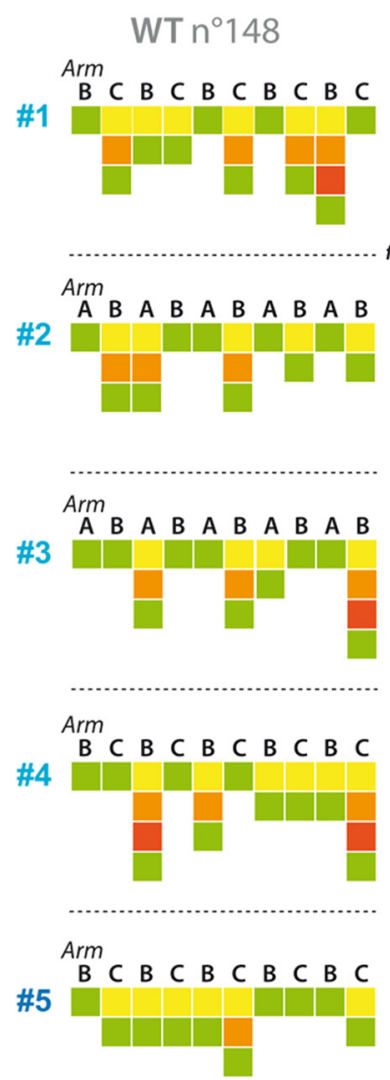

A2

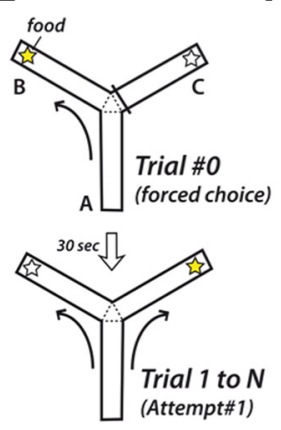

A3

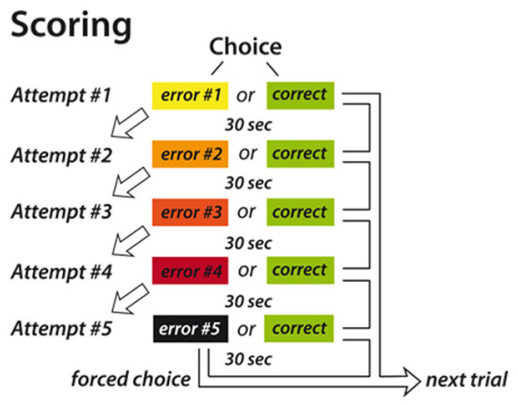

\section{C1 Global learning}
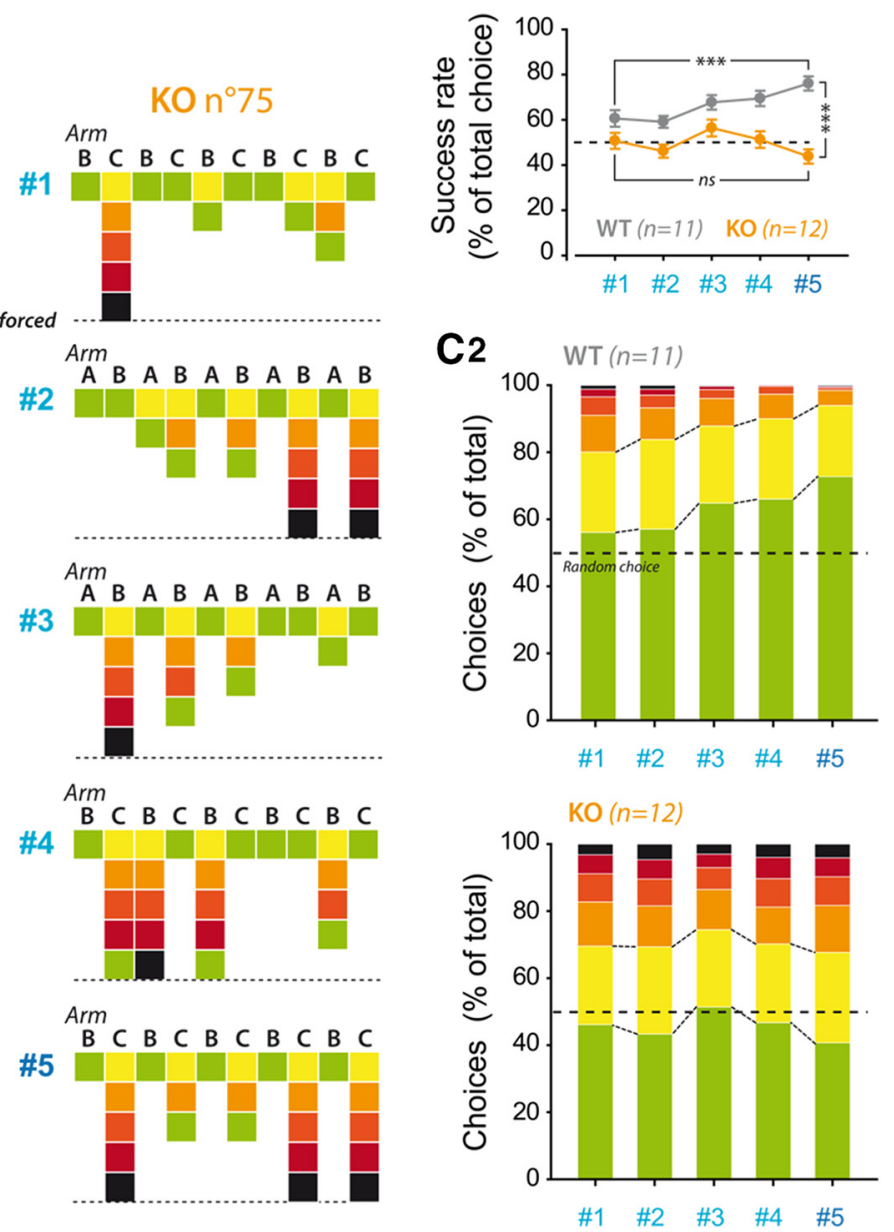

Figure 1. Ophn1-deficient mice are incompetent at spatial working memory tests and exhibit perseverative behavior. $\boldsymbol{A},(\boldsymbol{A} 1, \boldsymbol{A} \mathbf{2})$ Protocol used for testing for spatial working memory performance in Ophn 1 WT and KO mice. After habituation, the learning phase includes 80 trials separated into 4 sessions of 20 trials (10 + 10, with 3 h delay) conducted in 4 consecutive days. A retrieval test $(10+10$ trials) is run $2-3 \mathrm{~d}$ after learning. High rank errors are defined as errors repeated more than twice (attempts $2-5)$. $\boldsymbol{B}$, Example of individual scoring exhibited by a WT or a K0 mouse during the protocol. C1, Time course of the success rate in WT and K0 mice during the learning and retrieval phases. Dashed line indicates a 0.5 success rate dictated by random choice. C2, Bar graphs represent the evolution of the different choices occurrence (marked in colors in accordance with individual scoring in $\boldsymbol{B}$ ) along the spatial working memory procedure in WT (top) and K0 (bottom) mice.

and lambda points were defined and adjusted to the same horizontal level. The used coordinates for caudal HPC were as follows: anteroposterior $-3.1-3.3 \mathrm{~mm}$, mediolateral $\pm 3.2-3.4 \mathrm{~mm}$, dorsoventral -4.0 $\mathrm{mm}$. In $\mathrm{mPFC}$ containing acute slices (see above), hippocampus-mPFC monosynaptic EPSCs and disynaptic IPSCs were elicited by $1 \mathrm{~ms}$ light pulse delivered by an ultrahigh-power $460 \mathrm{~nm}$ LED (Prizmatix) at maximal intensity. All included cells were recorded in layer $\mathrm{V}$ of the IL region, as they consistently receive more excitatory inputs from the hippocampal region (Y.H. laboratory; data not shown). As for above-mentioned experiments, data were recorded with a Multiclamp700B (Molecular
Devices), filtered at $2 \mathrm{kHz}$, and digitized at $10 \mathrm{kHz}$. Data were acquired and analyzed with pClamp10.2 (Molecular Devices).

\section{PKA phosphorylation in mPFC tissues}

Animals were killed by cervical dislocation, and their brains were rapidly dissected out and processed further at $4^{\circ} \mathrm{C}$. The PFC were isolated and immediately homogenized or snap-frozen in liquid nitrogen. The PFC tissues were homogenized in TPS buffer $(0.32 \mathrm{~m}$ sucrose, 4 mM HEPES) containing $1 \times$ protease inhibitor cocktail (Calbiochem) alone or added with $1 \times$ phosphatase inhibitor cocktail (Pierce Biotechnology). Protein 
was quantified by Bradford assay. An equal amount of protein $(10 \mu \mathrm{g})$ was separated on $12 \%$ or $4 \%-20 \%$ SDS-polyacrylamide gels and transferred to nitrocellulose membranes at $4^{\circ} \mathrm{C}$ for Western blot analysis. The membranes were blocked in 5\% BSA in PBS containing $0.1 \%$ Tween 20 for $1 \mathrm{~h}$ at room temperature and incubated with the relevant antibody. The blots were incubated overnight at $4^{\circ} \mathrm{C}$ with the primary antibodies diluted in blocking solution: 1/1000 dilution of anti-phospho-(Ser/ Thr) PKA substrate antibody (Cell Signaling Technology), and 1/1000 dilution of antioligophrenin-1. Membranes were also probed with $1 / 5000$ dilution of anti- $\beta$-tubulin (SigmaAldrich), used as a loading control, allowing signal normalization. The membranes were washed and incubated in the appropriate AlexaFluor-488/-647 coupled secondary antibodies diluted 1/2000 for $1 \mathrm{~h}$ followed by direct reading membranes on Bio-Rad Pharos FX plus. The density of immune blots was measured using ImageJ software. Phosphorylation rate was determined by ratios between phosphorylated proteins and the $\beta$-tubulin loading control.

\section{Statistics}

Detailed statistics are described in each figure legend and are accessible in Table 1. For all tests, statistical difference was considered at $p<0.05$.

\section{Results}

Ophn1 deficiency in mice leads to aberrant perseverative behaviors in a spatial working memory test

Based on previous observations unraveling a lack of cued fear extinction behavior in Ophn1-deficient mice (Khelfaoui et al., 2014), we embarked on a more specific investigation to test the executive functions supported by the mPFC. Thus, we assessed the ability of Ophn1 WT and KO mice to learn an alternation rule with a time delay in the Y-maze. This task is known to mobilize spatial working memory in the $\mathrm{mPFC}$ and hippocampus (Benchenane et al., 2010; Gordon, 2011) (Fig. 1A). All along the training phase, Ophn1 WT progressively improved their performance, reaching a success rate close to 0.7 (70\%), which was maintained during a remote test (success rate WT\#1 vs WT\#5: $p<0.001$; Fig. 1C1). In stark contrast, all along the training and the testing phases, Ophn1 KO mice did not perform better than a random score rate $(50 \%)$ (success rate $\mathrm{KO} \# 1$ vs $\mathrm{KO} \# 5$ : $p<0.447$; WT\#5 vs KO\#5: $p<0.001$; Fig. $1 C 1)$, thus not displaying apparent sign of alternation rule learning. In addition to this poor performance, Ophn1 KO mice displayed another characteristic phenotype: the increased occurrence of repetitive errors (i.e., when the animal kept choosing the wrong arm several times in a row) (Fig. 1B,C2). This was scored as high rank errors, which normally disappear with training in
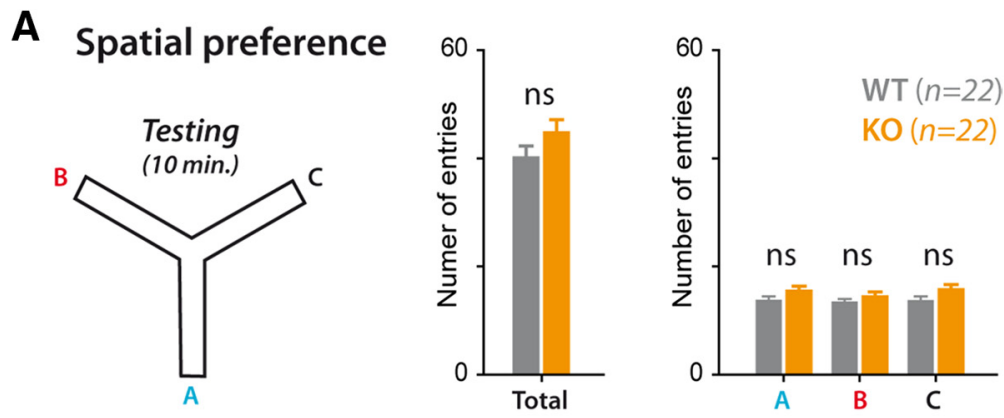

\section{B Turning preferences}
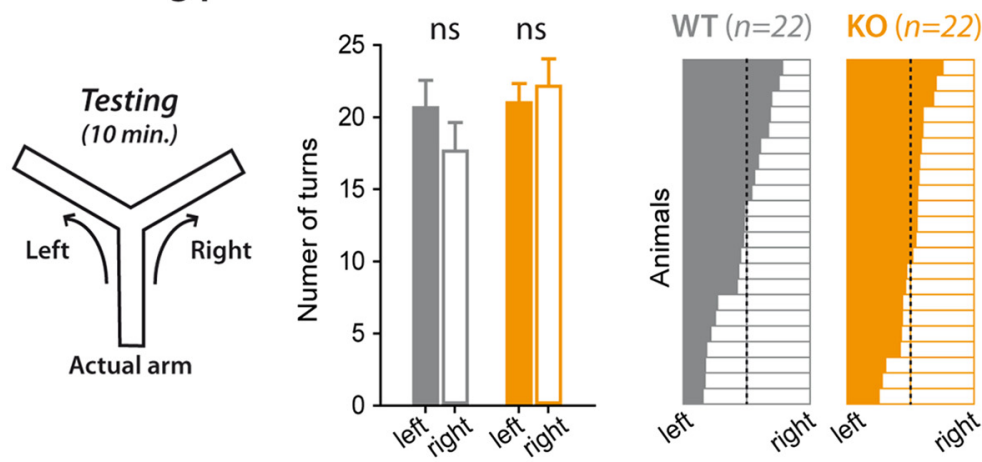

\section{Spatial novelty preference}
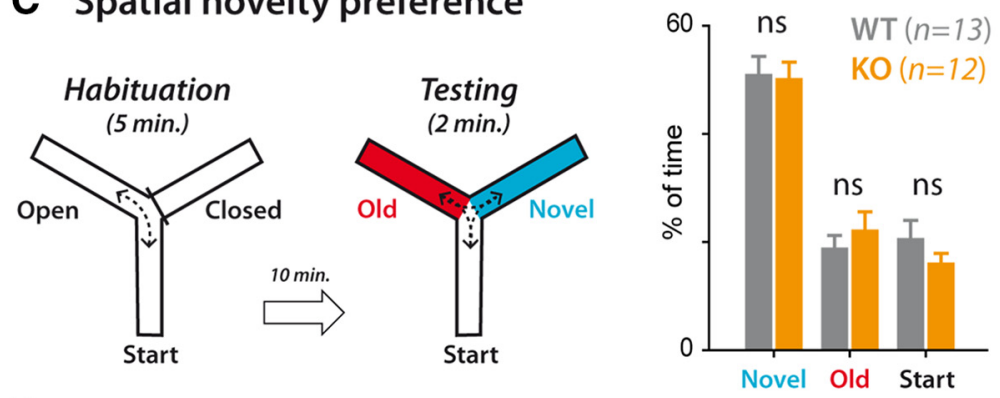

\section{Spontaneous alternation}
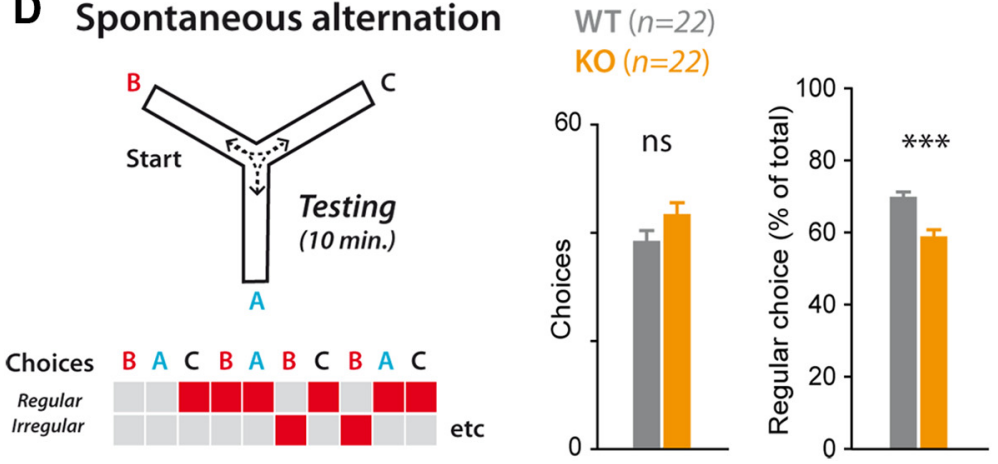

Figure 2. Ophn1-deficient mice show deficit in spontaneous alteration task, but not in other Y-maze based tasks. $\boldsymbol{A}$, The exploration activity and spatial preference of Ophn 1 WT and $\mathrm{KO}$ mice were tested by counting the total number of arm entries (left) or entries into each arm (right). $\boldsymbol{B}$, The natural tendency of mice in turning left or right was also tested. $\boldsymbol{C}$, Spatial reference memory was tested using spatial novelty task (see Materials and Methods) and was not impaired in Ophn $1 \mathrm{KO}$ mice. Number of animals is indicated. D, Based on the innate tendency of mice to explore a prior unvisited arm, regular/irregular choices were defined. $K 0$ mice displayed less such tendency than their WT littermates in spontaneous alteration task, which indicates a spatial working memory problem. ${ }^{* * *} p<0.001, t$-test.

WT mice (high rank errors: WT\#1 vs WT\#5, $p<0.001$; Fig. 1C2). High rank errors were strikingly and consistently present in $\mathrm{KO}$ mice (high rank errors: $\mathrm{KO \# 1}$ vs $\mathrm{KO \# 5,} p<0.683$; WT\#5 vs KO\#5: $p<0.001$; Fig. 1C2). Control spatial preference tests showed that these high rank mistakes were not due to turning 


\section{A1 Y-maze behavior analysis}

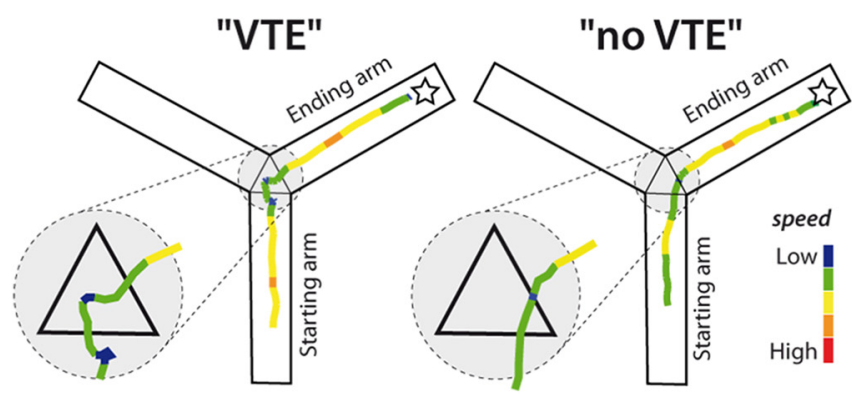

B1

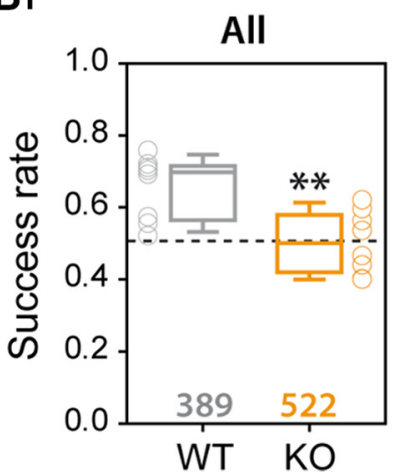

B2

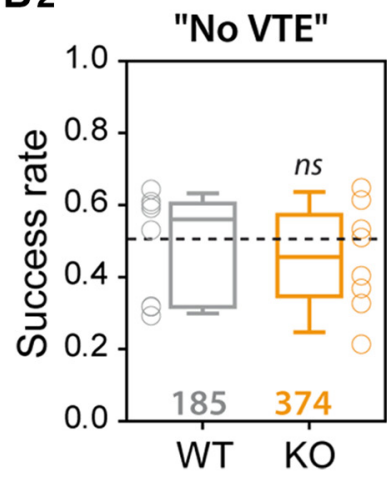

A2

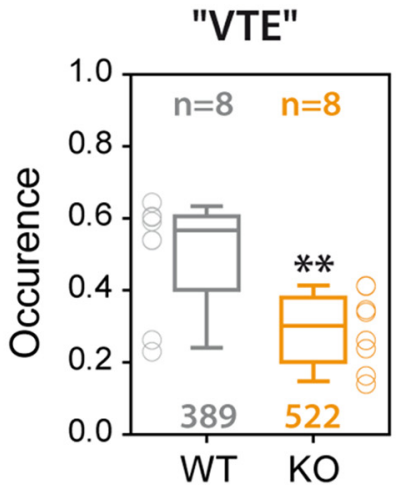

B3

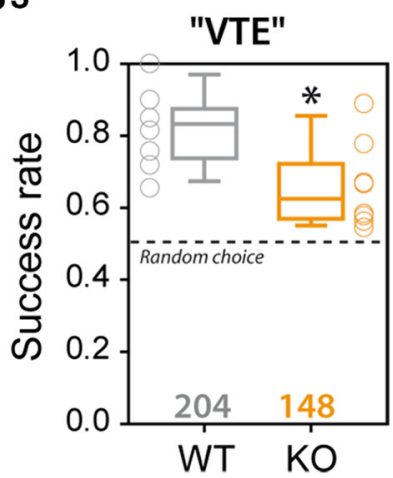

Figure 3. Ophn1 K0 mice display deliberation and cognitive deficits at spatial working memory tests. A1, Examples of mouse video-tracking in the Y-maze showing typical "wavering" as VTE or "no wavering" NO VTE trajectories at the bifurcation (choice) area of the maze (zoomed in inset). Speed of motion is color-coded from blue (low) to red (high). A2, Bar graph represents the occurrence of VTE/wavering in WT and KO mice. $\boldsymbol{B} 1-\boldsymbol{B} 3$, Detailed analysis of the success rates depending on the occurrence of VTE. When no VTE/wavering is measured, the success rate is random in both genotypes (B2); whereas upon VTE behavior, high success rates are observed (B3). However, K0 mice performance upon VTE remains lower than that of WT mice. The number of analyzed trials is indicated. ${ }^{*} p<0.05 ;{ }^{* *} p<0.01$.

preferences (Fig. $2 B$ ) and argued against navigation abnormalities in the maze (Fig. $2 A$ ) or short-term spatial reference memory preferences (Fig. 2C). Interestingly, decreased spontaneous alternation was found in Ophn1 KO mice (Fig. 2D). Together with previous reports from our laboratory (Khelfaoui et al., 2014), these results confirmed that $O p h n 1$ deficiency in mice leads to behavioral perseveration, a phenotype classically attributed to mPFC dysfunction.

\section{Ophn1-deficient mice display low occurrence of deliberative} behaviors and cognitive impairments

Interestingly, when mice make a choice before the bifurcation area (Fig. $3 A$ ), they display VTE behavior, reflecting a deliberative process (Redish, 2016). We first characterized VTE behavior in WT mice. During VTE behavior, the trajectory of mice appears to waver on approaching the bifurcation area, which is easily detectable in videos. Specifically, we observe a slower and less linear displacement at the crossing point compared with the starting or ending arm (Fig. 3A1). Importantly, the occurrence of VTE during trials ("VTE trials") was associated with high choice accuracy (success rate: "VTE trials": $0.82 \pm 0.04$; "no VTE trial": $0.49 \pm$ 0.05, $p<0.001$; Fig. 3B2,B3). In stark contrast, in Ophn1 KO mice, the occurrence of VTE behaviors was lower ("VTE trials": WT vs KO, $p<0.001$; Fig. 3A2) and the success rate of "VTE trials" was lower and close to random (success rate "VTE": $0.66 \pm$ 0.04 ; WT vs KO, $p=0.002$; Fig. $3 B 3$ ). From these results, we conclude that the deterioration of Ophn1 KO mice performance in Y-maze resides both in cognitive impairment and the low occurrence of deliberation-driven decision making.

Neurophysiology of mPFC networks in Ophn1-deficient mice Next, we examined the physiology of some of the neuronal circuits known to support spatial working memory, namely, mPFC neuronal circuits and the long-range hippocampal projections that are likely to allow the synchronization between hippocampal and mPFC neuronal networks (Laroche et al., 2000; Benchenane et al., 2010). To achieve this, we performed whole-cell patchclamp recordings from $\mathrm{mPFC}$ neurons in acute slices of Ophn1 WT and KO mice (Figs. 4, 5). First, we compared various passive cellular properties of recorded $\mathrm{mPFC}$ neurons but failed in identifying any genotype-based differences (Table 2) with one noticeable exception: the holding current was found to be higher in $\mathrm{KO}$ cells, suggesting that $\mathrm{mPFC}$ neurons were slightly more depolarized (see Table 1, statistical values). The spiking pattern activities were also comparable between WT and KO mice (Fig. 4B). Next, we tested the functionality of hippocampal projections to layer $\mathrm{V}$ cells of IL (intralimbic mPFC) (see Materials and Methods) using an optogenetic approach based on the stereotaxic injection of an AAV-ChR2-GFP within caudal hippocampus (Fig. 4C) (Zhang et al., 2015). We then photo-stimulated long-range hippocampal fibers carrying channel-rhodopsin in mPFC slices to allow the recording of direct monosynaptic excitatory transmission (Fig. $4 C 2$ ) and the feedforward recruitment of local mPFC interneurons. Their activation by hippocampal inputs lead to a 


\section{A electrophysiological recordings ( $\mathrm{mPFC}$ )}

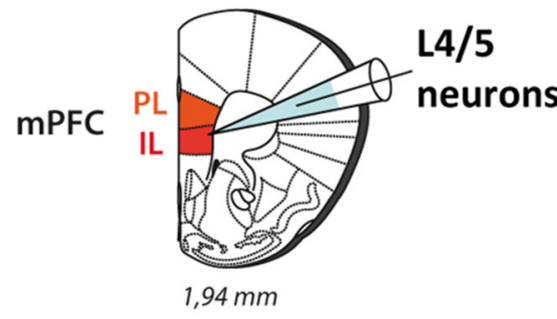

B Spiking patterns
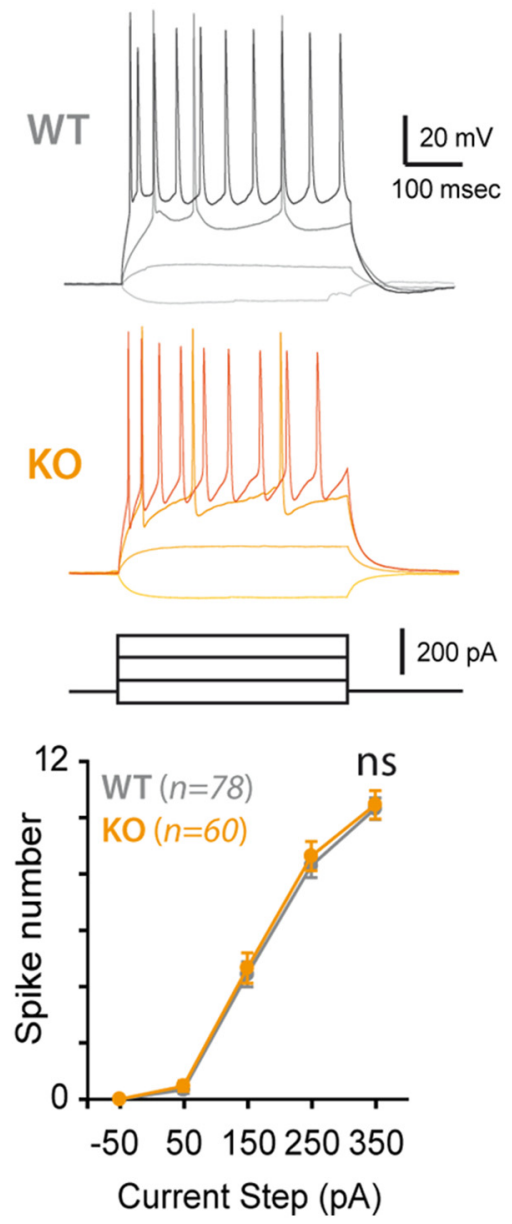

\section{C1 Hippocampus to mPFC (feed-forward circuit)}

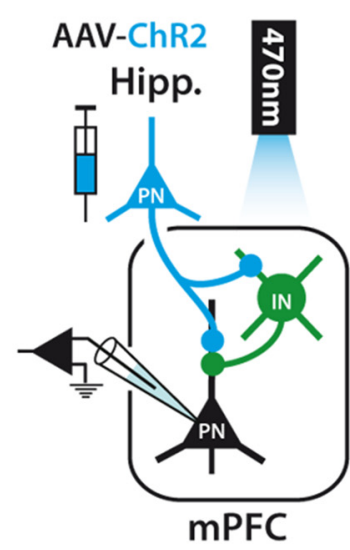

\section{injection areas}
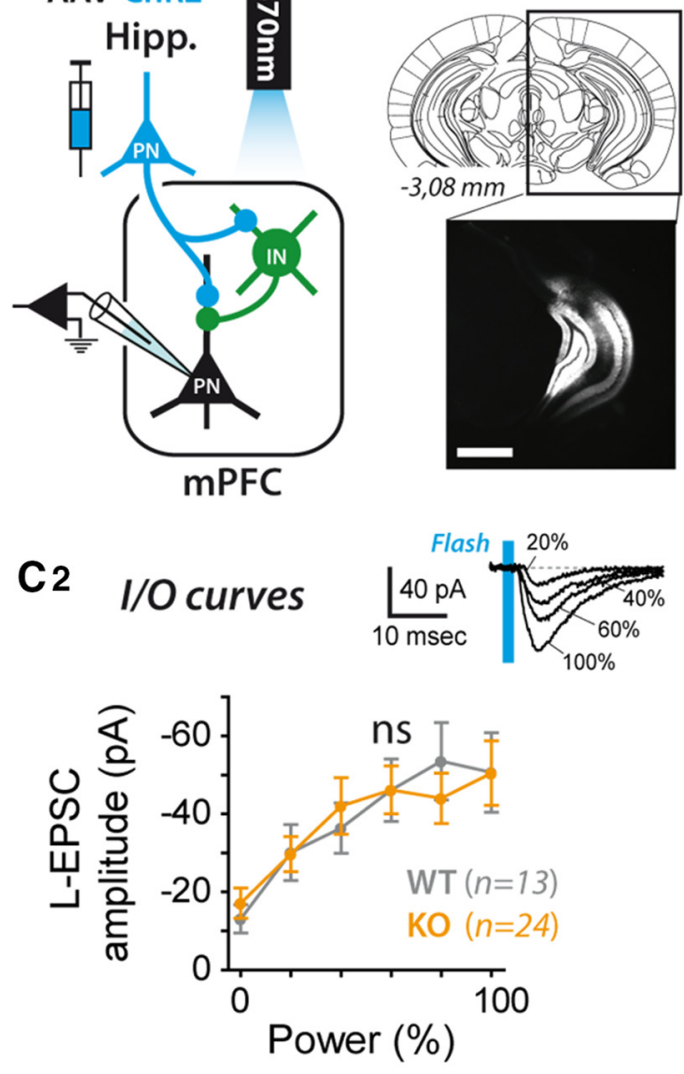

\section{C3 Feed Forward Inhibition}

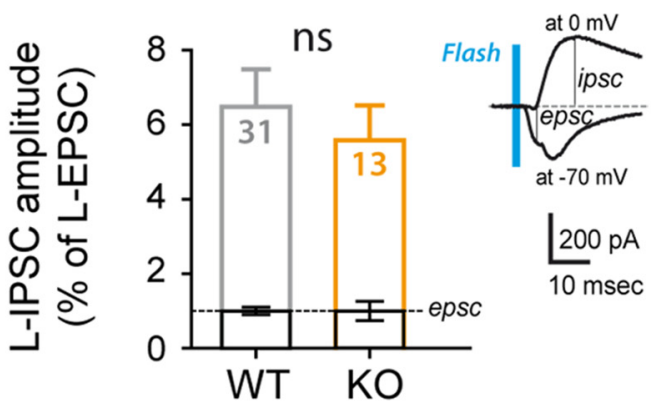

Figure 4. In vitro electrophysiological recordings did not reveal a functional impact of the mutation on hippocampus-mPFC interconnections. $\boldsymbol{A}$, Scheme of the acute slice preparation in which IL neurons were recorded using whole-cell patch-clamp technique. $\boldsymbol{B}$, Spiking activities of mPFC neurons in WT and KO preparations were indistinguishable. The number of recorded cells is indicated. $\boldsymbol{C}$, Study of hippocampal-mPFC feedforward circuits using optogenetic stimulation. An AAV-ChR2-YFP vector was injected into caudal hippocampus to allow stimulating direct hippocampal projections to the mPFC following delivery of flashes of blue light (1 ms, $470 \mathrm{~nm}$ ). mPFC neurons were recorded at -70 and $0 \mathrm{mV}$ to allow detecting monosynaptic EPSCs ( 2 , C3) and disynaptic IPSCs (C3). $\mathbf{C 2}$, Input/output curves of light evoked EPSCs in both genotypes. C3, Relative amplitude of light-evoked disynaptic IPSCs in both genotypes. The number of recordings is indicated. Insets, Typical recordings.

GABAA-mediated outward current at a holding potential of 0 $\mathrm{mV}$ and that is delayed by a few milliseconds (Fig. 4C3). Importantly, these two synaptic conductances are thought to be involved in the control of behaviorally relevant neuronal assemblies and in their synchronization during spatial working memory-dependent tasks (Rolls et al., 2008). Interestingly, these projections appeared to be functionally preserved when Ophn1 is mutated in mice (Fig. 4C). Although some hip- pocampal projections toward specific $\mathrm{mPFC}$ cell populations may be impacted by Ophn1 deletion, it suggested that behavioral deficits must reside from local neuronal networks defects either in hippocampus or in mPFC.

PKA increases synaptic noise in the PFC of Ophn1 KO mice Neuronal networks have to extract meaningful sensory-evoked signal from background synaptic noise, the level of which de- 
A1

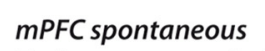
Excitatory transmission

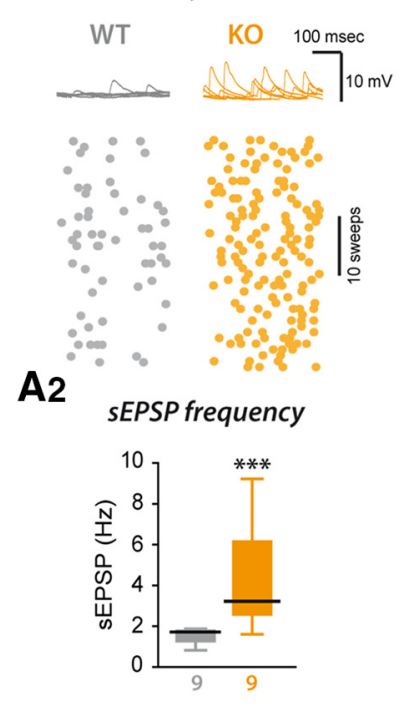

B1

PKA (P)-targets (PFC)

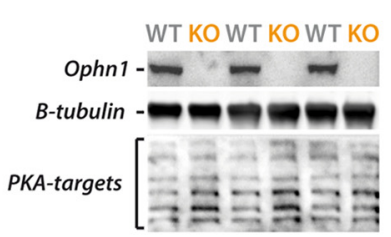

C1 spontaneous activity

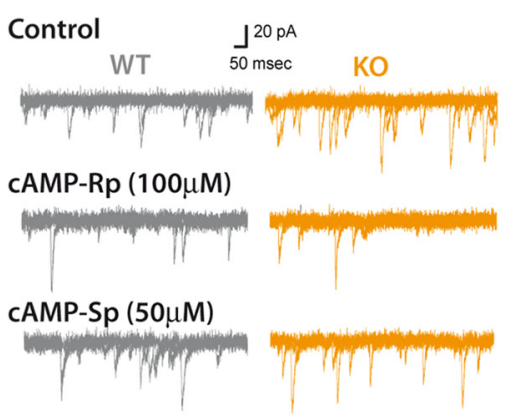

B2

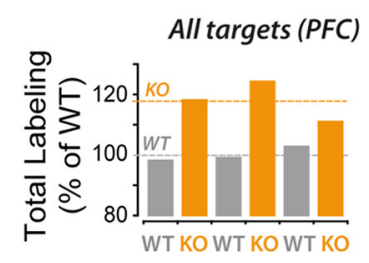

B3

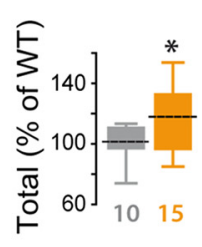

$\mathrm{C}_{2}$

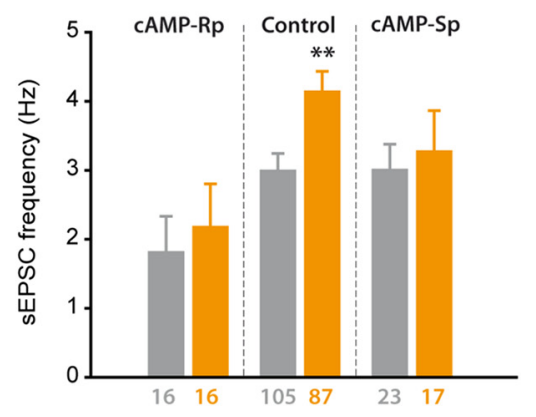

Figure 5. Ophn1 deficiency leads to a PKA-dependent increase of synaptic noise in the mPFC. A1, Typical recordings of spontaneous excitatory potentials, and K0 preparations show more frequent events. A2, Bar graphs represent the SEPSP frequency in mPFC neurons in WT (gray) and K0 (orange) preparations. ${ }^{* * *} p<0.001$. $\boldsymbol{B}$, PKA-mediated phosphorylation was tested using Western blots and anti-phospho-PKA target antibodies. B1-B3, Ophn1 K0 samples showed increased signal intensities compared with WT homogenates. The number of animals is indicated. ${ }^{*} p<$ 0.05. C, Modulation of spontaneous EPSC frequency by pharmacological manipulations of PKA activity. C1, Typical electrophysiological recordings in the various tested conditions. CAMPS-Rp: competitive inhibiting CAMP-dependent PKA; CAMPS-Sp: competitive activating CAMP-dependent PKA. C2, Bar graph represents the average excitatory drives received by mPFC neurons in control conditions and following application of CAMPS-Rp or CAMPS-Sp. The number of recordings is indicated. ${ }^{* *} p<0.01$.

Table 2. mPFC cell properties

\begin{tabular}{lllll}
\hline Tested condition & $\begin{array}{l}\text { WT cells } \\
(n=106)\end{array}$ & $\begin{array}{l}\text { K0 cells } \\
(n=105)\end{array}$ & Statistics test & $p$ \\
\hline $\begin{array}{l}\text { Leak current } \\
\text { (holding }-70 \mathrm{mV})\end{array}$ & $-18 \pm 6 \mathrm{pA}$ & $-57 \pm 3 \mathrm{pA}$ & $\begin{array}{c}\text { Mann-Whitney } \\
\text { Rank Sum Test }\end{array}$ & 0.001 \\
Access resistance & $25 \pm 1 \mathrm{~m} \Omega$ & $25 \pm 1 \mathrm{~m} \Omega$ & $\begin{array}{c}\text { Mann-Whitney } \\
\text { Rank Sum Test }\end{array}$ & 0.922 \\
Input resistance & $202 \pm 12 \mathrm{~m} \Omega$ & $213 \pm 12 \mathrm{~m} \Omega$ & $\begin{array}{c}\text { Mann-Whitney } \\
\text { Rank Sum Test }\end{array}$ & 0.467 \\
Cell capacitance & $24 \pm 1$ & $18 \pm 1 \mathrm{pA}$ & $\begin{array}{c}\text { Mann-Whitney } \\
\text { Rank Sum Test }\end{array}$ & 0.921 \\
\hline
\end{tabular}

pends on several neuromodulators and signaling pathways, including those involving PKA (Geurts et al., 2004; Arnsten et al., 2005; Rolls et al., 2008). We therefore recorded the spontaneous excitatory synaptic events in $\mathrm{mPFC}$ neurons from WT and $\mathrm{KO}$ mice. In control conditions, both in voltage and current-clamp mode, we detected a strong increase in the frequency of spontaneous excitatory events in Ophn1 KO preparations, without any effect on event amplitudes (sEPSP frequency WT vs KO: $p=$ 0.004; Fig. 5A2; sEPSC frequency WT vs KO: $p<0.001$; Fig. 5C2).

Next, we tested for possible involvement of PKA activity in controlling spontaneous excitatory transmission in $\mathrm{mPFC}$ slices (Fig. 5C). Beforehand, we wanted to confirm our previous results that PKA activity was increased in some, but not all, brain regions in Ophn1 KO mice (Khelfaoui et al., 2014). To this aim, we ran biochemical analysis of PKA-mediated phosphorylation in homogenates from Ophn1 WT and KO prefrontal cortices (see Materials and Methods; Fig. 5B). Using an anti-phospho-PKA-target antibody, we compared PKA-mediated phosphorylation levels between WT and KO mice (Fig. 5B1-B3). A moderate but significant increase of phosphorylation levels of PKA targets was observed in Ophn1 KO samples (total labeling WT vs KO, $p<0.05$;
Fig. 5B3), confirming previous results obtained with enzymatic assay in mouse cerebral cortex homogenates.

Then, sEPSC frequency was assessed in WT and KO slices in presence of PKA-signaling antagonist cAMPS-Rp $(100 \mu \mathrm{M})$ or PKA-signaling agonist cAMPS-Sp $(50 \mu \mathrm{M})$ (Fig. 5C). Interestingly, PKA modulators were efficient in affecting sEPSC frequency recorded in $\mathrm{mPFC}$ neurons in both genotypes, but measured frequencies in low-PKA (cAMP-Rp) and high-PKA (cAMP-Sp) conditions were indistinguishable between genotypes (cAMPS-Sp: sEPSC frequency WT vs KO: $p=0.798$; Fig. 5C2). Thus, the increased "synaptic noise" observed in Ophn1 KO mPFC preparations may result from higher endogenous PKA activity level, and possibly to neuronal cell depolarization (see above). Interestingly, under the presence of the well-tolerated and permeable PKA pathway antagonist cAMPS-Rp, the sEPSC frequency in Ophn1 KO preparations was comparable with the one found in WT mice (cAMPS-Rp: sEPSC frequency WT vs KO: $p=$ 0.289; Fig. 5C2), akin to a process of normalization of synaptic noise levels in vivo in Ophn1-deficient mice (Taylor et al., 1999).

\section{Increasing PKA activity in mPFC of WT mice mimicked Ophn1 KO phenotype}

At first, we tested whether PKA activity changes in $\mathrm{mPFC}$ were necessary and sufficient to mimic the SWM deficits observed in Ophn1 KO mice. To achieve this, we manipulated PKA activity levels in the $\mathrm{mPFC}$ of WT and KO mice running the DSA test. To that end, mice were implanted to allow intra-mPFC delivery of PKA modulators before the DSA test sessions (Fig. 6). We first tried to reproduce previous experiments showing that an increase of PKA levels in PFC impacts SWM performance in WT mice (Taylor et al., 1999). Here, as in Figure 3, the success rate scoring was sorted according to the absence or presence of a "VTE" behavior. A first group of WT animals were implanted within mPFC or dHPC (Fig. 6B) and submitted to DSA learning (Fig. 


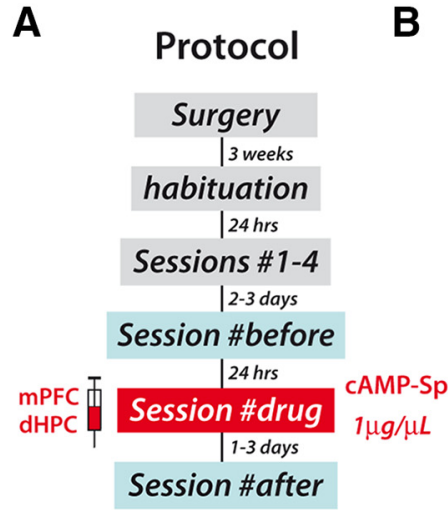

C1 1 cAMP-Sp (mPFC)

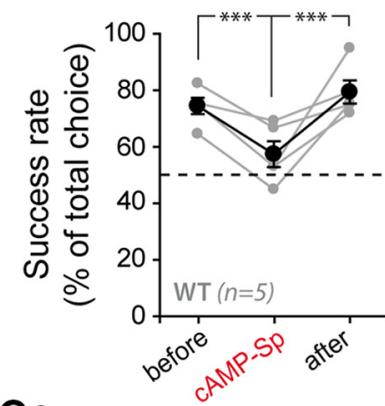

$\mathrm{C}_{2}$

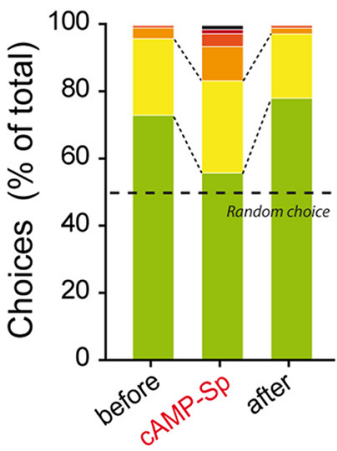

B

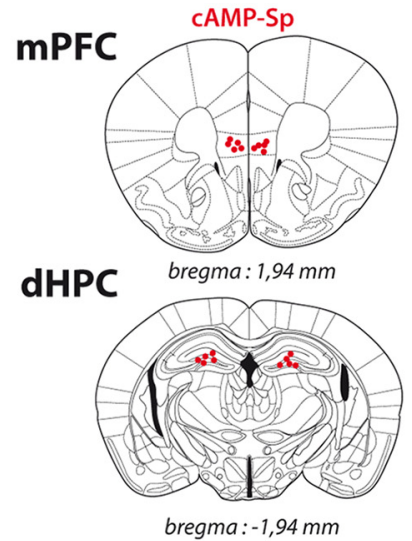

D1 CAMP-Sp (dHPC)

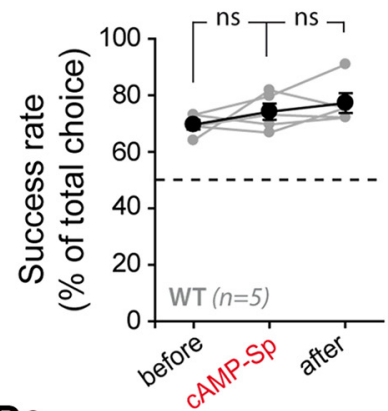

D2

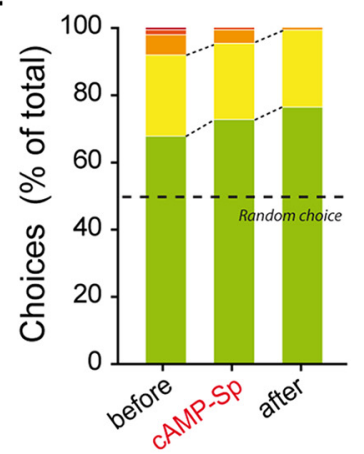

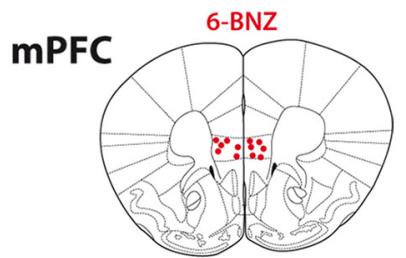

\section{E1 6-BNZ-CAMP $(\mathrm{mPFC})(10 \mu g / \mu L)$}

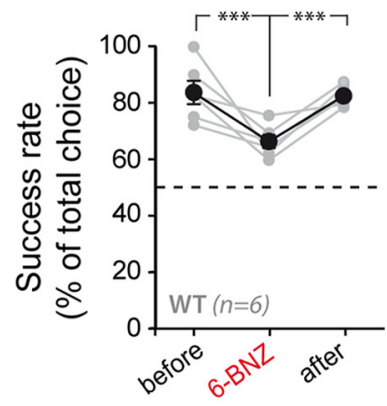

E2

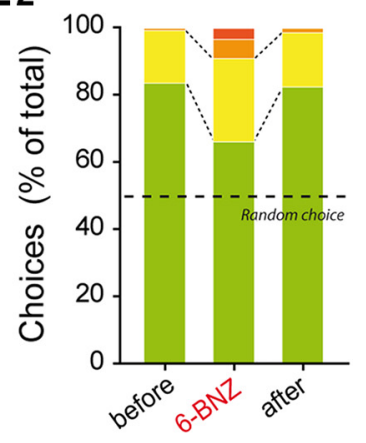

$\mathbf{F}$

"VTE" in CAMP-Sp ( $\mathrm{mPFC})$
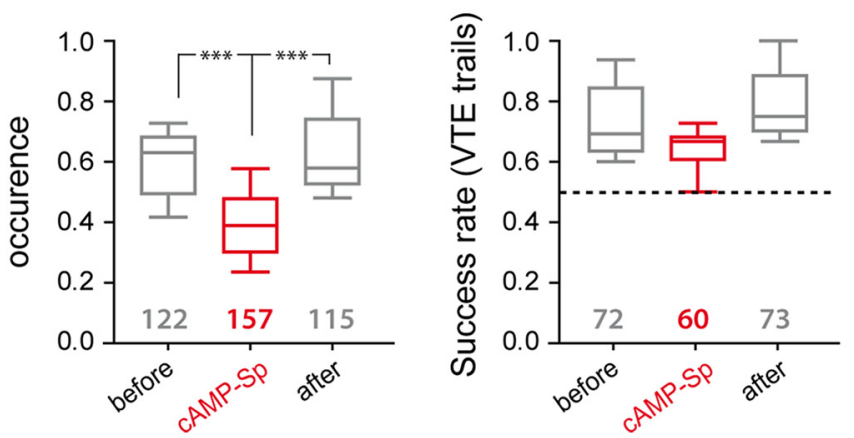

Figure 6. Increasing PKA activity in MPFC phenocopies Ophn1 KO performance drop at the DSA test. $A$, Experimental scheme includes cannula implantation, learning of DSA rule, and three sessions of testing before, during, and after delivery of the PKA activators CAMPS-Sp or 6-BNZ-CAMP in the mPFC or in the dHPC of WT animals. $\boldsymbol{B}$, Injection loci for all included animals. $\boldsymbol{C}-\boldsymbol{E}$, Scoring of the success rate of WT animal performance at the DSA test before, upon, and after drug delivery in the mPFC (C1, $\mathbf{C}, \mathbf{E 1}, \mathbf{E 2})$ or dHPC (D1, D2). F, VTE/wavering expression and consecutive choice accuracy were analyzed in the CAMP-sp/mPFC condition. The number of analyzed trials is indicated. ${ }^{* * *} p<0.001$.

$6 A)$. After accomplishment of the DSA learning, animal performance was collected the day before, during, and the day after (Taylor et al., 1999) intra-mPFC injection of the well-tolerated PKA agonist (cAMPS-Sp, $1 \mu \mathrm{g} / \mu \mathrm{l}$ ) (Taylor et al., 1999), The re- sults showed that increased PKA activity in mPFC affected not only the local network activity (Fig. $5 C$ ) but also animal performances (success rate: WT drug cAMP-Sp vs before or vs after: $p<$ 0.001 ; Fig. $6 C 1, C 2$ ) with a pronounced decrease in the occurrence 
A

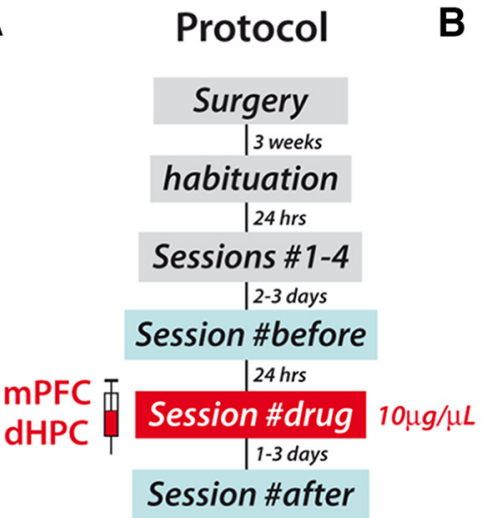

C1 CAMP-Rp (mPFC)

$\mathrm{C}_{2}$
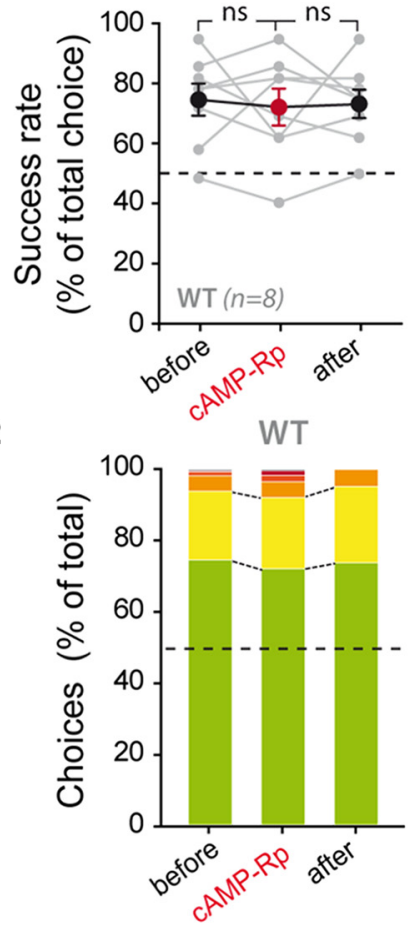

B Injection areas
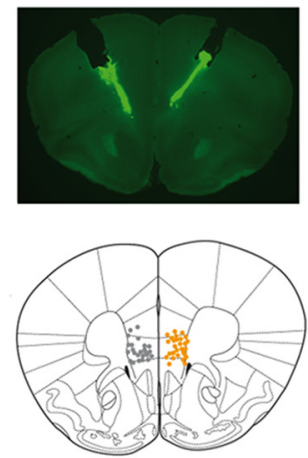

bregma: $1,94 \mathrm{~mm}$
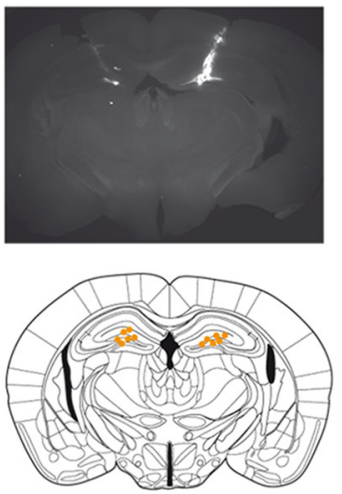

bregma : $-1,94 \mathrm{~mm}$

D1 CAMP-Rp (dHPC)
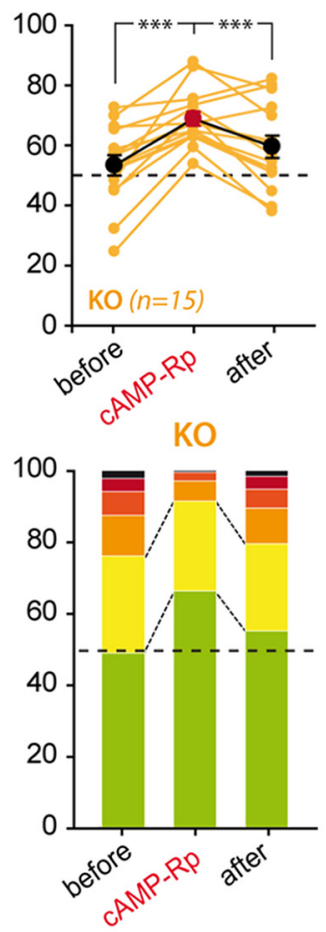

D2
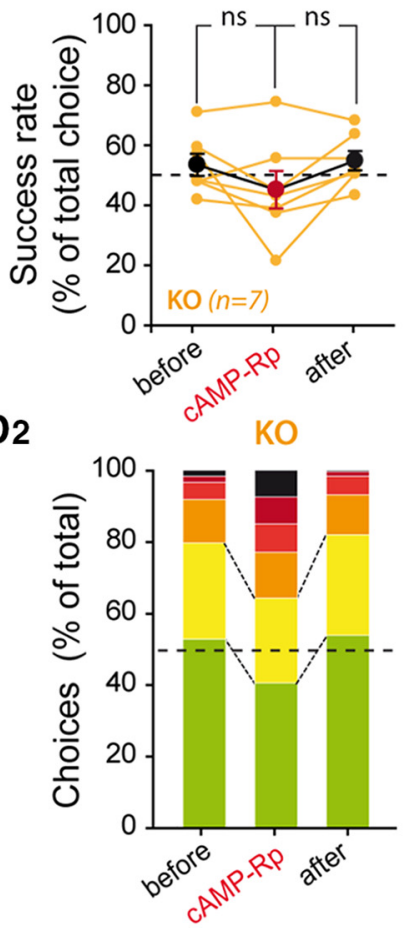

E1

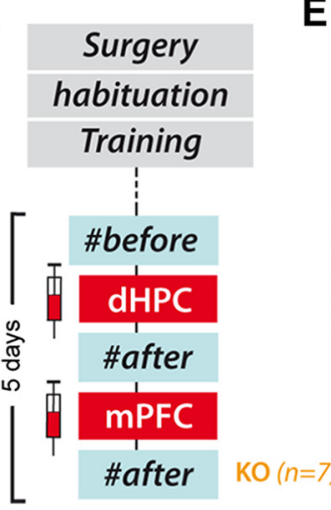

E2 2 dHPC $\mathrm{mPFC}$

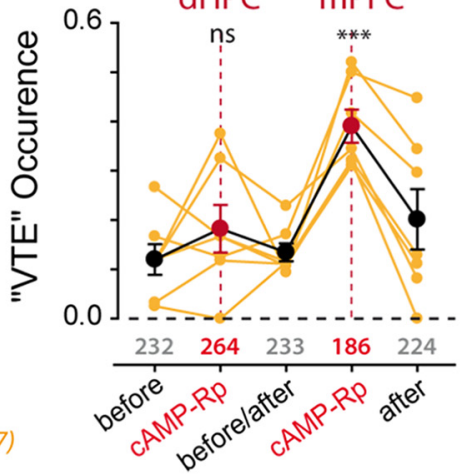

E3

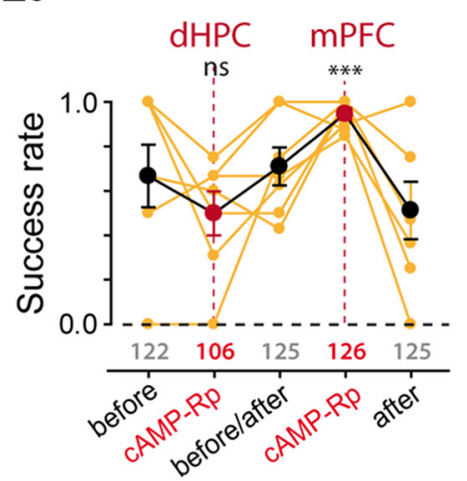

Figure 7. Complete phenotypic normalization of Ophn $1 \mathrm{KO}$ mice following pharmacological inactivation of PKA in the mPFC. A, Description of our protocol that includes cannula implantation, learning of DSA rule, and 3 testing sessions done before, during, and after delivery of the PKA blocker CAMPS-Rp in mPFC or DHPC of KO and WT animals. $\boldsymbol{B}$, Injection loci for all included animals. C1, C2,Scoring of the success rate of WT and KO animal performance at the DSA test before/during/after cAMPS-Rp application in mPFC. The number of animals is indicated. Upon cAMPS-Rp infusion, success rate of $\mathrm{KO}$ animals improves, and high rank error rate strongly decreases. D1, D2, A similar CAMPS-Rp infusion within $\mathrm{AHPC}$ of $\mathrm{KO}$ animals did not reproduce the effects within mPFC. E1, A group of mice was implanted both bilaterally in DHPC and mPFC to assess for VTE/wavering occurrence and choice accuracy (as in Fig. 2). cAMPS-Rp was successively injected in dHPC and then in mPFC. E2, Effect of CAMPS-Rp injection on the occurrence of VTE. There is strong increase observed following mPFC injection. E3, Scoring of the choice accuracy following a VTE/wavering behavior. The number of trials is indicated. ${ }^{* * *} p<0.001$. 

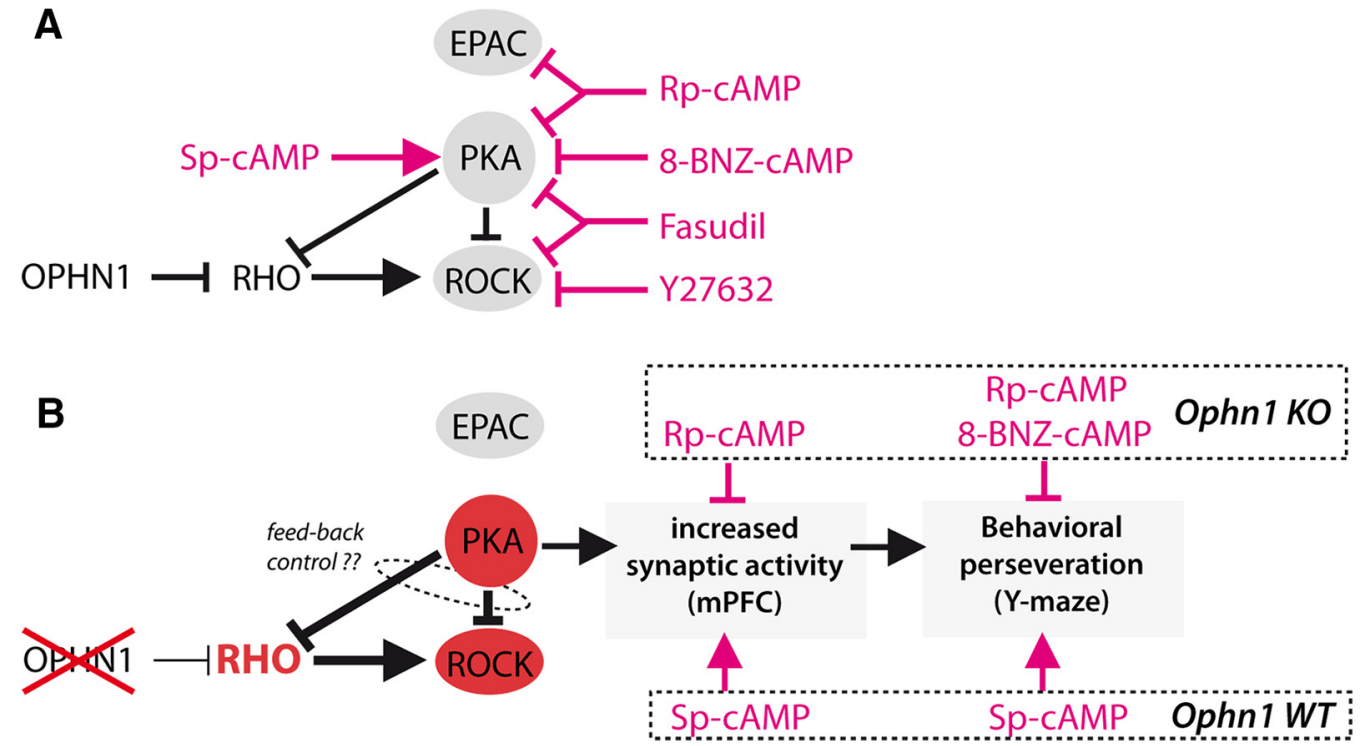

Figure 8. Results summary. A, Pharmacological tools acting on various kinases that have been used or discussed in in vivo experiments on Ophn1-deficient mice in the present study. $\boldsymbol{B}$, Scheme describing the proposed sequence of molecular, cellular, network events leading to behavioral perseveration in Ophn $1 \mathrm{KO}$ mice.

of VTE behaviors (VTE: drug vs before or vs after: $p<0.001$; Fig. $6 F$, left) and a nonsignificant difference in the success rate with VTE behavior (success rate with VTE: drug vs before or vs after: $p=0.784$; Fig. $6 F$, right). In addition, we also noticed the appearance of high rank errors (drug vs before or vs after: $p=0.002$; Fig. $6 C 2$ ), indicating perseveration behavior. Interestingly, similar results were obtained following $\mathrm{MPFC}$ injections of 6-BNZ-cAMP $(10 \mu \mathrm{g} / \mu \mathrm{l})$, a PKA activator with a strong selectivity for PKA over guanine nucleotide exchange factor cAMP-GEF (Epac; see Discussion) (high rank errors: drug vs before or vs after: $p<0.001$; Fig. $6 E$ ). Thus, an increase of PKA activity in mPFC, but not dHPC (Fig. 6D), is sufficient to mimic the deficit in SWM tests that we observed in Ophn1 $\mathrm{KO}$ mice.

\section{Decreased PKA activity in PFC of KO mice restores cognitive performance}

We then directly tested whether PKA hyperactivity in mPFC of

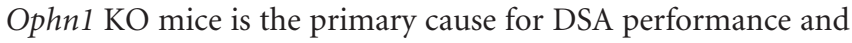
perseveration behavior. For this, we scored $\mathrm{KO}$ animal performance while PKA activity was decreased in the PFC through local infusion of cAMPS-Rp (10 $\mu \mathrm{g} / \mu \mathrm{l}$; Fig. 7). As a control, we analyzed the effect of a similar treatment performed in WT animals (Fig. 7C, left panels) or in the dHPC of KO mice (Fig. 7D). In KO, but not WT, animals (Fig. $7 C$ ), decreasing PKA activity in the mPFC significantly improved SWM performance: indeed, all treated $\mathrm{KO}$ mice displayed a noticeable increase of success rate (success rate WT drug vs before or vs after: $p=0.684$, success rate KO drug vs before or vs after: $p<0.001$; Fig. 7C1) accompanied with a decrease of high rank errors (high rank errors KO before vs drug vs after: $p<0.001$; Fig. 7C2). The same pharmacological treatment applied in dHPC of KO mice had no positive effect on DSA test (Fig. 7D) as for lower dose of cAMPS-Rp in mPFC of KO mice $(1 \mu \mathrm{g} / \mu \mathrm{l}$; data not shown).

Finally, to determine whether we achieved a real normalization of animal VTE behavior, we also scored VTE/wavering occurrence and its relation to success rates. The tested group of mice were bilaterally implanted in both in MPFC and AHPC, in which cAMPS-Rp could be allowed to diffuse successively in dHPC and mPFC with a $5 \mathrm{~d}$ protocol (Fig. 7E1). As shown in Figure 7,
mPFC, but not dHPC, infusion was associated with a significant increase of VTE (VTE occurrence KO: mPFC drug vs all other conditions: $p<0.001$; Fig. 7E2), which was observed together with an increase in the choice accuracy in VTE trials (choice accuracy KO: mPFC drug vs all other conditions: $p<0.001$; Fig. 7E3).

Therefore, our results collectively led us to propose that PKA hyperactivity associated with $O p h n 1$ deficiency in mice is necessary and sufficient to explain the spatial alternation deficit.

\section{Discussion}

In the present work, we thoroughly characterized a pronounced behavioral phenotype displayed by Ophn1-deficient mice in a Y-maze-based spatial working memory test. Our results led us to conclude that the poor performance of $\mathrm{KO}$ mice results from a lack of deliberation (VTE/wavering) during decision-making and to cognitive (low choice accuracy even when VTE/wavering is present) and adaptive (no self-correction leading to perseverative behavior) deficits. Meanwhile, we could establish that Ophn1 deficiency is accompanied by an increase of excitatory synaptic noise in the mPFC. Interestingly, we could phenocopy Ophn1 deficiency phenotype in the DSA test through the local activation of PKA in WT mPFC. Finally, our attempts to inhibit the pathological PKA hyperactivity in $\mathrm{KO} \mathrm{mPFC}$ corrected all observed behavioral deficits (Fig. 8).

\section{PKA activity and synaptic noise in absence of Ophn1}

Peak performance at a DSA test has been shown to depend on mobilization of neuronal assemblies in the MPFC following hippocampal instructions, which synchronizes circuit activities in the theta range (Benchenane et al., 2010). Importantly, computational studies suggest that activation of mPFC networks, which have been proposed to allow pattern completion during cognitive processes, such as working memory, is sensitive to synaptic noise (Rolls et al., 2008). In line with a previous study (Khelfaoui et al., 2014), the present data obtained using electrophysiological approaches support the notion that hyperactivity of PKA in Ophn1deficient mice generated synaptic noise in mPFC region (Fig. 5). If it is well known that PKA-mediated phosphorylation of RhoA and ROCK could inhibit RhoA pathway (Newell-Litwa et al., 2011), 
yet the origin for the increased PKA activity in Ophn1-deficient mice remains to be understood. It may result from the loss of function of its Rho-GAP activity and translational and/or post-translational driven feedback mechanism controlling RhoA activity (Nusser et al., 2006). To our knowledge, no evidence is available for a direct link between PKA and Ophn1. Some answers may be provided by a more detailed analysis of AKAPs (A Kinase-Anchoring Proteins; a family of scaffold proteins that regulate PKA activity) in neuronal populations (Diviani et al., 2006; Wang et al., 2006).

Synaptic noise in the mPFC region is thought to cause some of the phenotypes observed in schizophrenic patients, which typically exhibited reduced signal-to-noise ratio and reduced phase locking in the PFC (Winterer et al., 2000). Among many mechanisms, cAMP/PKA signaling pathway seems well positioned to finely tune the signal-to-noise ratio. Indeed, dopamine release in the PFC is thought to mimic the reward prediction signal and efficiently modulate PFC-HPC synchrony during the DSA test (Benchenane et al., 2010), as well as tune the signal-to-noise ratio within mPFC networks (Rolls et al., 2008). Furthermore, DA release within the $\mathrm{mPFC}$ involves cAMP/PKA-dependent signaling (Arnsten et al., 2005), opening the possibility that the hyperactivity of PKA in Ophn1-deficient mice could shunt the ability of dopaminergic inputs to provide rewarding signals within the mPFC. This absence could contribute to the absence of selfcorrection during the DSA test, thus generating the perseverative behavior. Interestingly, because a normalization of $\mathrm{KO}$ animal behavior is obtained even after training is completed, the reward circuits allowing rule learning and reinforcement must be maintained in the absence of Ophn1. Future experiments will be required to test how Ophn1 deletion may disrupt dopaminergic modulation by changing cAMP/PKA signaling activity.

Separating cognitive and deliberative deficits using DSA test Interestingly, Benchenane et al. (2010) showed that the level of PFC-HPC synchrony before the entrance of the crossroad point in the Y-maze was correlated with choice accuracy and hence renamed as the "decision point." We here show that choice accuracy at the decision point is also highly correlated with the occurrence of a VTE/wavering behavior, typified by deceleration at the crossroad point and slow-motion sequence preceded by a subsequent acceleration (Fig. 3A1), thereby reproducing pioneer studies describing VTE behaviors (Redish, 2016). Therefore, VTE/ wavering at the decision point is considered as a reliable indication of working memory processing and deliberation leading to decision making (Fig. 3B). If combined with choice accuracy determination, it could help in characterizing real SWR-related decisions (VTE vs no VTE) and cognitive-related choices (accuracy of "VTE trials"). This further dissection of the behavioral sequence allowed a better understanding of the poor performance of Ophn1 KO mice. Thus, the incorrect choices could be attributed both to a deliberation deficit adding onto cognitive-based failures even when they do pay attention to the task (Fig. 3). Strikingly, all these parameters were completely normalized following pharmacological PKA activity correction within the $\mathrm{MPFC}$ but not in the dHPC (Fig. 7), thus shedding light onto the crucial role of PKA deregulation associated with Ophn1 deficiency within the PFC in this cognitive task. An interesting observation is the normalization of high accuracy-related VTE behaviors in PKA-manipulated $\mathrm{KO}$ mice, thus showing the capacity of prefrontal circuits in establishing relevant cognitive actions even though Ophn1 expression is absent in this structure.

\section{Pharmacological correction of behavior in trained Ophn1-deficient adult mice}

We think that our findings are opening a new avenue in the understanding of the pathophysiology of intellectual disabilities by showing that some of very handicapping consequences of monogenic mutations may be largely accessible to pharmacological treatment in affected adults. Another interesting finding reported here is that the poor performance of Ophn1-mutated animals in the Y-maze test was not due to defective learning capabilities, but rather due to a lack of behavioral control normally assumed by the PFC during the DSA task. Indeed, we could phenotypically normalize animal behavior after the training procedure was terminated, demonstrating that the $\mathrm{KO}$ mice acquired the DSA rule during the learning phase. Together with the observation that $\mathrm{AHPC}$ PKA modulations in WT and KO mice did not display strong effects (Figs. 6, 7), we propose that the described increase in PKA activity in the hippocampus of Ophn1 KO mice (Khelfaoui et al., 2014) and the related lack of PKA-dependent LTP at DG-CA3 synapses did not play a major role in DSA coding in mice. Similarly, synaptic deficits were previously reported in hippocampal circuits due to Ophn1 deletion (Nadif Kasri et al., 2009, 2011; Nakano-Kobayashi et al., 2009, 2014; Powell et al., 2012). Even though these may reflect important direct cellular and molecular consequences to the deletion, they may not be central to the presently described cognitive impairment.

Recent studies have shown that, in addition to PKA, cAMP activates the Epac, thereby controlling HCN channels (Wang et al., 2006). However, in contrast to PKA, Epac does not seem to activate CREB in vitro. We first measured $\mathrm{HCN}$ channels activity in mPFC cells from Ophn1 WT and KO mice but could not find any difference in the outward current generated during hyperpolarizing steps (data not shown) in both conditions. Next, we used conditional Ophn1 animals to test whether deletion of Ophn1 was sufficient to lead to P-CREB increase in a cell-autonomous way. Indeed, compared with nontransfected cells, mPFC cells in which Ophn1 was deleted exhibited higher P-CREB levels as their untransfected neighbors, as assessed by P-CREB immunochemistry (see Materials and Methods; data not shown). Although not definitively excluding any effect of Ophn1 condition on Epac signaling, these experiments strongly support that a cell-specific increase in PKA activity is associated with the loss of function of Ophn1 in the mPFC, at the origin of an increase in synaptic noise in this structure.

In conclusion, we report here that Ophn1 deficiency in mice leads to an unanticipated destabilization of the cAMP/PKA signaling pathway that is causing a major incapacity to access working memories. As pharmacological approaches successfully restored normal performance and physiological parameters, we think that our report is opening a new therapeutic avenue for Ophn1-related syndromes. Beyond this, it should contribute to the heterogeneity of pathological consequences of Ophn1 deficiencies in humans.

\section{References}

Arnsten AF, Ramos BP, Birnbaum SG, Taylor JR (2005) Protein kinase A as a therapeutic target for memory disorders: rationale and challenges. Trends Mol Med 11:121-128. CrossRef Medline

Benchenane K, Peyrache A, Khamassi M, Tierney PL, Gioanni Y, Battaglia FP, Wiener SI (2010) Coherent theta oscillations and reorganization of spike timing in the hippocampal-prefrontal network upon learning. Neuron 66:921-936. CrossRef Medline

Billuart P, Bienvenu T, Ronce N, des Portes V, Vinet MC, Zemni R, Roest Crollius H, Carrié A, Fauchereau F, Cherry M, Briault S, Hamel B, Fryns JP, Beldjord C, Kahn A, Moraine C, Chelly J (1998) Oligophrenin-1 
encodes a rhoGAP protein involved in X-linked mental retardation. Nature 392:923-926. CrossRef Medline

Di Prisco GV, Huang W, Buffington SA, Hsu CC, Bonnen PE, Placzek AN, Sidrauski C, Krnjević K, Kaufman RJ, Walter P, Costa-Mattioli M (2014) Translational control of mGluR-dependent long-term depression and object-place learning by eIF2 $\alpha$. Nat Neurosci 17:1073-1082. CrossRef Medline

Diviani D, Baisamy L, Appert-Collin A (2006) AKAP-Lbc: a molecular scaffold for the integration of cyclic AMP and Rho transduction pathways. Eur J Cell Biol 85:603-610. CrossRef Medline

Geurts HM, Verté S, Oosterlaan J, Roeyers H, Sergeant JA (2004) How specific are executive functioning deficits in attention deficit hyperactivity disorder and autism? J Child Psychol Psychiatry 45:836-854. CrossRef Medline

Gordon JA (2011) Oscillations and hippocampal-prefrontal synchrony. Curr Opin Neurobiol 21:486-491. CrossRef Medline

Houbaert X, Zhang CL, Gambino F, Lepleux M, Deshors M, Normand E, Levet F, Ramos M, Billuart P, Chelly J, Herzog E, Humeau Y (2013) Target-specific vulnerability of excitatory synapses leads to deficits in associative memory in a model of intellectual disorder. J Neurosci 33: 13805-13819. CrossRef Medline

Humeau Y, Herry C, Kemp N, Shaban H, Fourcaudot E, Bissière S, Lüthi A (2005) Dendritic spine heterogeneity determines afferent-specific Hebbian plasticity in the amygdala. Neuron 45:119-131. CrossRef Medline

Jay TM, Gurden H, Yamaguchi T (1998) Rapid increase in PKA activity during long-term potentiation in the hippocampal afferent fibre system to the prefrontal cortex in vivo. Eur J Neurosci 10:3302-3306. CrossRef Medline

Kesner RP, Churchwell JC (2011) An analysis of rat prefrontal cortex in mediating executive function. Neurobiol Learn Mem 96:417-431. CrossRef Medline

Khelfaoui M, Denis C, van Galen E, de Bock F, Schmitt A, Houbron C, Morice E, Giros B, Ramakers G, Fagni L, Chelly J, Nosten-Bertrand M, Billuart P (2007) Loss of X-linked mental retardation gene oligophrenin1 in mice impairs spatial memory and leads to ventricular enlargement and dendritic spine immaturity. J Neurosci 27:9439-9450. CrossRef Medline

Khelfaoui M, Gambino F, Houbaert X, Ragazzon B, Müller C, Carta M, Lanore F, Srikumar BN, Gastrein P, Lepleux M, Zhang CL, Kneib M, Poulain B, Reibel-Foisset S, Vitale N, Chelly J, Billuart P, Lüthi A, Humeau Y (2014) Lack of the presynaptic RhoGAP protein oligophrenin1 leads to cognitive disabilities through dysregulation of the cAMP/PKA signalling pathway. Philos Trans R Soc Lond B Biol Sci 369:20130160. CrossRef Medline

Laroche S, Davis S, Jay TM (2000) Plasticity at hippocampal to prefrontal cortex synapses: dual roles in working memory and consolidation. Hippocampus 10:438-446. CrossRef Medline

Meziane H, Khelfaoui M, Morello N, Hiba B, Calcagno E, Reibel-Foisset S, Selloum M, Chelly J, Humeau Y, Riet F, Zanni G, Herault Y, Bienvenu T, Giustetto M, Billuart P (2016) Fasudil treatment in adult reverses behavioural changes and brain ventricular enlargement in Oligophrenin-1 mouse model of intellectual disability. Hum Mol Genet 25:2314-2323. CrossRef Medline

Nadif Kasri N, Nakano-Kobayashi A, Malinow R, Li B, Van Aelst L (2009) The Rho-linked mental retardation protein oligophrenin-1 controls synapse maturation and plasticity by stabilizing AMPA receptors. Genes Dev 23:1289-1302. CrossRef Medline
Nadif Kasri N, Nakano-Kobayashi A, Van Aelst L (2011) Rapid synthesis of the X-linked mental retardation protein OPHN1 mediates mGluRdependent LTD through interaction with the endocytic machinery. Neuron 72:300-315. CrossRef Medline

Nakano-Kobayashi A, Kasri NN, Newey SE, Van Aelst L (2009) The Rholinked mental retardation protein OPHN1 controls synaptic vesicle endocytosis via endophilin A1. Curr Biol 19:1133-1139. CrossRef Medline

Nakano-Kobayashi A, Tai Y, Nadif Kasri N, Van Aelst L (2014) The X-linked mental retardation protein OPHN1 interacts with Homer1b/c to control spine endocytic zone positioning and expression of synaptic potentiation. J Neurosci 34:8665-8671. CrossRef Medline

Newell-Litwa KA, Horwitz AR (2011) Cell migration: PKA and RhoA set the pace. Curr Biol 21:R596-R598. CrossRef Medline

Nusser N, Gosmanova E, Makarova N, Fujiwara Y, Yang L, Guo F, Luo Y, Zheng Y, Tigyi G (2006) Serine phosphorylation differentially affects RhoA binding to effectors: implications to NGF-induced neurite outgrowth. Cell Signal 18:704-714. CrossRef Medline

Piton A, Gauthier J, Hamdan FF, Lafrenière RG, Yang Y, Henrion E, Laurent S, Noreau A, Thibodeau P, Karemera L, Spiegelman D, Kuku F, Duguay J, Destroismaisons L, Jolivet P, Côté M, Lachapelle K, Diallo O, Raymond A, Marineau C, et al. (2011) Systematic resequencing of X-chromosome synaptic genes in autism spectrum disorder and schizophrenia. Mol Psychiatry 16:867-880. CrossRef Medline

Powell AD, Gill KK, Saintot PP, Jiruska P, Chelly J, Billuart P, Jefferys JG (2012) Rapid reversal of impaired inhibitory and excitatory transmission but not spine dysgenesis in a mouse model of mental retardation. J Physiol 590:763-776. CrossRef Medline

Redish AD (2016) Vicarious trial and error. Nat Rev Neurosci 17:147-159. CrossRef Medline

Rolls ET, Loh M, Deco G, Winterer G (2008) Computational models of schizophrenia and dopamine modulation in the prefrontal cortex. Nat Rev Neurosci 9:696-709. CrossRef Medline

Sumiyoshi C, Kawakubo Y, Suga M, Sumiyoshi T, Kasai K (2011) Impaired ability to organize information in individuals with autism spectrum disorders and their siblings. Neurosci Res 69:252-257. CrossRef Medline

Taylor JR, Birnbaum S, Ubriani R, Arnsten AF (1999) Activation of cAMPdependent protein kinase $\mathrm{A}$ in prefrontal cortex impairs working memory performance. J Neurosci 19:RC23. Medline

van Bokhoven H (2011) Genetic and epigenetic networks in intellectual disabilities. Annu Rev Genet 45:81-104. CrossRef Medline

Wang GW, Cai JX (2006) Disconnection of the hippocampal-prefrontal cortical circuits impairs spatial working memory performance in rats. Behav Brain Res 175:329-336. CrossRef Medline

Wang Y, Chen Y, Chen M, Xu W (2006) AKAPs competing peptide HT31 disrupts the inhibitory effect of PKA on RhoA activity. Oncol Rep 16:755761. CrossRef Medline

Wikenheiser AM, Redish AD (2015) Hippocampal theta sequences reflect current goals. Nat Neurosci 18:289-294. CrossRef Medline

Winterer G, Ziller M, Dorn H, Frick K, Mulert C, Wuebben Y, Herrmann WM, Coppola R (2000) Schizophrenia: reduced signal-to-noise ratio and impaired phase-locking during information processing. Clin Neurophysiol 111:837-849. CrossRef Medline

Zhang CL, Houbaert X, Lepleux M, Deshors M, Normand E, Gambino F, Herzog E, Humeau Y (2015) The hippocampo-amygdala control of contextual fear expression is affected in a model of intellectual disability. Brain Struct Funct 220:3673-3682. CrossRef Medline 